NBSIR $74-610$

\title{
Investigation of Procedures for
}

Determination of Thermal Performance

Characteristics of Plastic Piping Used in Housing

Max T'yon

Center for Building Technology

Institute for Applied Technology

National Bureau of Standards

Washington, D. C. 20234

November 1974

Interim Report for Period

July 1972 through June 1973

Prepared for

Office of Research and Technology

Department of Housing and Urban Development

Washington, D. C. 20410 

NBSIR 74-610

\section{INVESTIGATION OF PROCEDURES FOR \\ DETERMINATION OF THERMAL PERFORMANCE \\ CHARACTERISTICS OF PLASTIC PIPING USED}

\section{IN HOUSING}

Max Tryon

Center for Building Technology

Institute for Applied Technology

National Bureau of Standards

Washington, D. C. 20234

November 1974

Interim Report for Period

July 1972 through June 1973

Prepared for

Office of Research and Technology

Department of Housing and Urban Development

Washington, D. C. 20410

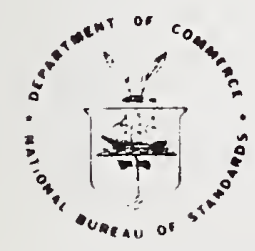

U. S. DEPARTMENT OF COMMERCE, Frederick B. Dent, Secretary

NATIONAL BUREAU OF STANDARDS, Richard w. Roberts. Director 
t 
Abstract.

1. Introduction

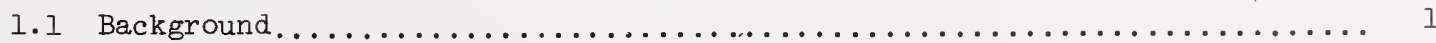

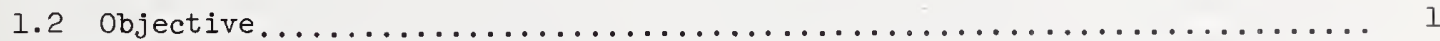

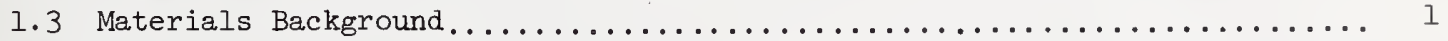

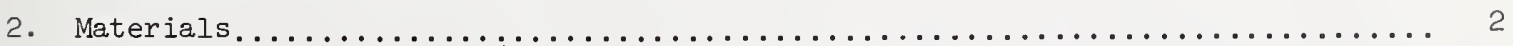

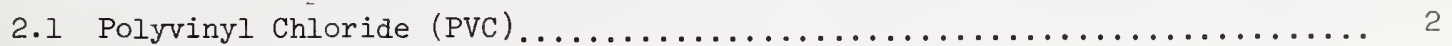

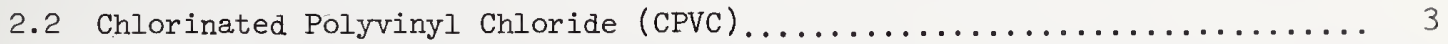

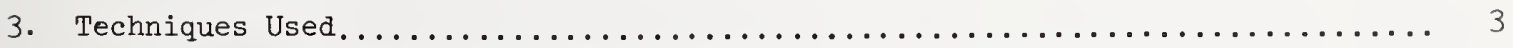

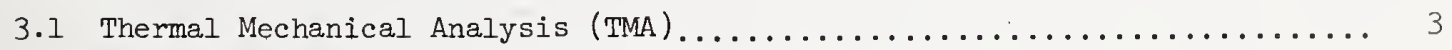

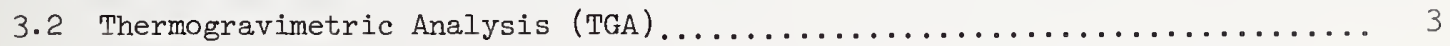

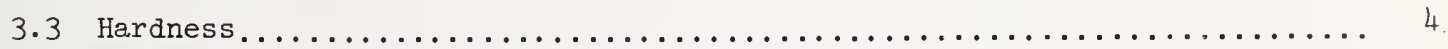

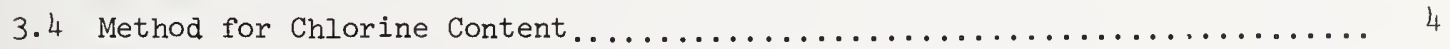

3.5 Aging Studies.....................................

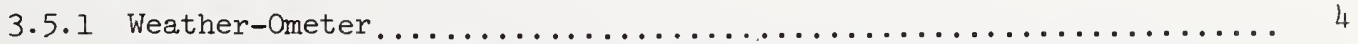

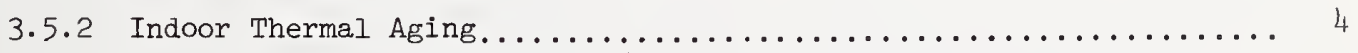

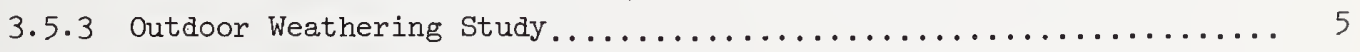

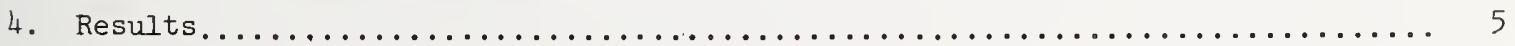

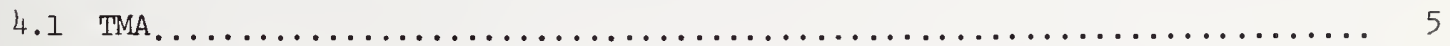

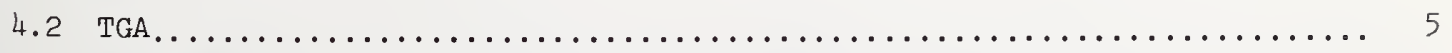

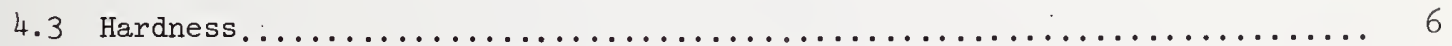

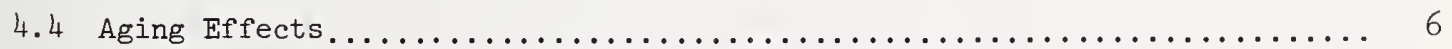

4.4 .1 Weather-Ometer Studies............................. 6

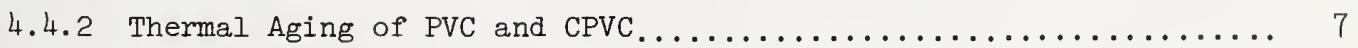

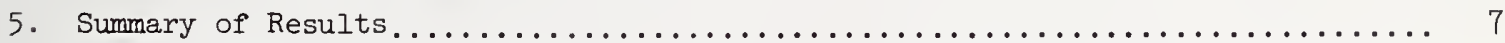

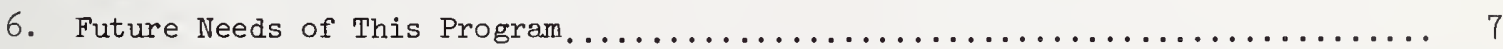

List of Tables

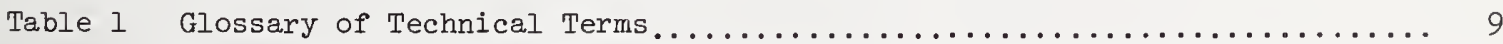

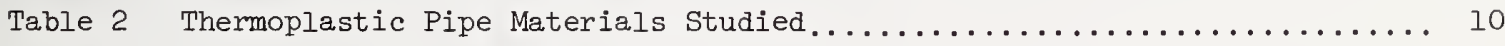

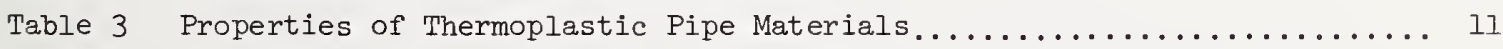

Table 4 Change in Hardness (Shore D) of PVC and CPVC Piping with Temperature.... 12

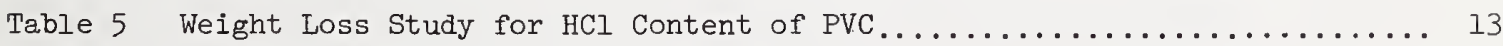

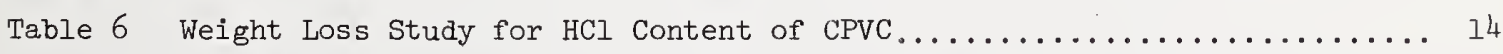

Table 7 Dimensional Changes of PVC-DWV Piping on Thermal Aging at $80^{\circ} \mathrm{C}\left(176^{\circ} \mathrm{F}\right) . .15$

Table 8 Decreases in Length $(\Delta \mathrm{L})$ of Piping on Heating to $90^{\circ} \mathrm{C}\left(194^{\circ} \mathrm{F}\right) \ldots \ldots$ 
Fig. 1 Thermomechanical Analyzer (TMA)

Fig. 2 Thermomechanical Analyzer (Detail)

Fig. 3 TMA Curves on Pipe Samples

Fig. 4 Thermogravimetric Analysis Apparatus (TGA)

Fig. 5 Thermogravimetric Analyzer (Detail)

Fig. 6 TGA Curves on Pipe Samples

Fig. 7 Hardness Apparatus

Fig. 8 Hardness Apparatus (Detail) 
Investigation of Procedures for Determination of Thermal

Performance Characteristics of Plastic Piping Used in Housing

Max Tryon

Abstract

This report is a study to determine the critical factors affecting the performance of thermoplastic plumbing piping materials. The emphasis in this preliminary study was on thermal properties such as the softening point, relaxation of thermal stress, glass transition temperature, hardness-temperature relationship, and decomposition temperature. The techniques used were thermal mechanical analysis (TMA), thermogravimetric analysis (TGA), and hardness. Preliminary results obtained on several pipe samples of PVC and CPVC commercial samples are reported.

Keywords: Chlorinated polyvinyl chloride; hardness; internal stress; plumbing; polyvinyl chloride; thermogravimetric analysis (TGA); thermal mechanical analysis (TMA); thermoplastic pipe; thermal properties.

\section{Introduction}

\section{I Background}

The rapid growth of the use of thermoplastic pipe, from its initial production in the United States in 1941 to the present annual volume of products valued at hundreds of millions of dollars, has made these materials an important part of the building construction industry. The initial plastic used for drain, waste, and vent (DWV) applications was polyvinyl chloride (PVC)(I); a more recent development is the use of chlorinated polyvinyl chloride (CPVC) for pressure distribution systems.

While, for the most part, plastic pipe has performed well, there have been some failures. These appear to be attributable to inadequate quality control, to the use of materials under conditions beyond their design capabilities, or to improper installation. To research piping materials the Department of Housing and Urban Development requested the National Bureau of Standards to perform studies on plumbing criteria and to provide technical advice concerning the adequacy of performance criteria for plastic pipe for housing. The work described in this report is part of that carried out in response to this request.

\subsection{Objective}

The objective of this work is to investigate the sensitivity of plastic pipe materials to temperature changes and to recommend test procedures and performance criteria for these materials. This report covers the results of initial studies of certain thermal properties of PVC-DWV piping.

\subsection{Materials Background}

The plastic materials used in the production of drain, waste, and vent pipe (DWV) and potable water distribution systems are thermoplastics [1], [2], [8](2). Thermoplastics are used because of their relatively low cost, the availability of raw materials and their ease of fabrication into the finished product with minimal losses due to waste or scrap. The properties of these materials which allow rapid production, etc. are primarily related to their thermoplastic characteristics. Thermoplastic materials (e.g. glass, PVC) can be readily shaped or formed under pressure and elevated temperatures. An essential

(I) Other thermoplastics such as acrylonitrile-butadiene-styrene terpolymer (ABS) and polybutene ( $\mathrm{PB}$ ) will be considered in a future study.

(2) Numbers in brackets indicate references to the literature. 
requirement for a useful thermoplastic material is that it should not deform at the temperatures of end use. Since plastic plumbing piping is subject to a range of temperatures during normal use, consideration must be given to its thermal response.

Possible thermal responses include: ( 1 ) expansion on heating (or contraction on cooling) denoted by the thermal expansion coefficient for the material; (2) stress relaxation; and (3) decomposition. The coefficient of thermal expansion must be considered in the design of the system to allow for movements due to temperature changes.

The second possible thermal response, stress relaxation, results from the manufacturing process. Plastic piping made of thermoplastic materials such as PVC and CPVC is produced by extrusion [8]. This involves the use of high pressures and elevated temperatures to cause the semi-fluid material to flow through an orifice to give the tubular shape. Sizing of the outside diameter is achieved by a die using either a positive internal air pressure or a negative external pressure to cause the hot tube to expand slightly against the inner wall of the sizing die which is cooler than the pipe. The piping is water-cooled (quenched) immediately upon leaving the sizing die in order to "freeze" the final dimensions and maintain the desired tolerances in diameter and roundness. The rate of flow of material during this process varies with the machinery design, the plastic used, the temperature of the plastic, and the molecular weight of the plastic. However, the rates may be in the range of 10-50 ft/minute. Under these conditions of high shear rate followed by rapid quenching, a high degree of orientation of the plastic results. This orientation is primarily in the direction of flow or length of the piping and gives a "grain" effect analogous to that in wood. The large polymer molecules are not only oriented, but stretched lengthwise along the length of the tubing. As a result, a high degree of internal stress may be present in the finished product. The amount of this stress is related to the rate of shear, rate of cooling, and molecular weight of the polymer. Figure 12 shows schematically the effect just described and indicates the various directions of anisotropy in the internal structure.

The internal stress which remains in the product is a result of two properties of the material. The first is the property known as the glass transition temperature $(3)$ and the second, the high viscosity of the material [8]. In order for the stress to be relieved, the material must be heated above its glass transition temperature for a sufficient length of time for the molecular stress to relax. The time required depends on the viscosity of the material.

Finally, at some higher temperature, decomposition will occur. This temperature is also characteristic of the material but may be altered by the manufacturing process; thus, it may be raised by certain additives or lowered by improper temperature control during processing. Again, for the piping to be useful, the decomposition temperature must be well above the expected use or exposure temperatures of the piping. The nature of the decomposition products must be taken into account in assessing fire hazards, as pointed out in the fire report [14] published earlier.

This report contains the results of preliminary studies of these three temperature effects for the PVC-DWV and CPVC pressure pipe samples described in Table 2. These pipes were selected as being of immediate interest. Aspects of performance which were not studied, but which may also be important, include stress-corrosion, slime generation, and long-term aging effects.

\section{Materials}

\section{I Polyvinyl chloride (PVC)}

Polyvinyl chloride is a resin prepared by the polymerization of vinyl chloride with or without the addition of small amounts of other monomers [12]. Some of the properties of this polymer are given in Table 3. The chlorine content given is the theoretical amount provided it is formed completely of vinyl chloride with no other monomers added. At this time, all of the PVC pipe manufactured for plumbing use is believed to be made of $100 \%$ vinyl chloride monomer.

(3) Table 1 is a glossary of technical terms used in this report. 


\subsection{Chlorinated Polyvinyl Chloride (CPVC)}

This is a resin prepared by the addition of chlorine to polyvinyl chloride to approximate the amount of one chlorine atom for each carbon atom in the polyvinyl chloride. The actual chlorine content is usually less than the theoretical amount. This resin is a newcomer to the plastics industry and its properties have not been as extensively studied as those of PVC. Also, the composition of CPVC is not as well defined as it is for PVC and so variations in the properties fo CPVC may be expected from batch to batch. The extent of these variations is not known so that the important properties need to be determined for each batch. Typical known property ranges are listed in Table 3.

\section{Techniques Used}

\subsection{Thermal Mechanical Analysis (TMA)}

The thermal mechanical analyzer used allowed the investigation and measurement of such properties of materials as: coefficient of linear expansion, melting point, softening point, internal stresses, and flow properties [3].

The apparatus consists of a mechanical section, shown in fj.gure 1 , and a control section. The mechanical section is made up of a sample area and probe with a probe positjonining sensor, a means for applying different loads on the probe, and a heater for controlling the sample temperature. The control section contains the electronic controls for programming of the sample temperature and a recorder for recording of the probe position (sample height) as a function of temperature or time.

In the procedure used in this study, ring-shaped samples about 1/4" long, were cut from the pipes with a saw, care being exercised to keep from overheating the sample. Smaller, roughly cubic, sections (see figure 12) were cut from the ring by cleaving with a sharp knife blade and a hammer; the final sample size was the wall thickness of the piping and the various orientation directions were marked on the sides of the cube with a felt-tip pen. The cut sides had to be relatively parallel to one another to prevent the sample from tilting, and the probe from slipping, during the test. The sample was measured with a micrometer and it was placed in the apparatus with the orientation of interest between the base and the probe (figure 2). The probe was lowered into contact with the sample and a selected weight applied to the pan atop the probe. The probe sensor was adjusted to give the proper pen position on the chart, the heater placed around the sample, the insulating flask placed around the heater, and the temperature program initiated by turning on the recorder. The choice of parameters such as probe type (ball tip or flat end), size of loading weight, heating rate, starting temperature, recorder sensitivity and range, were all based on previous investigations and were recorded on the chart. The probe displacement was recorded as a function of temperature.

\section{Typical results are shown in figure 3.}

\subsection{Thermogravimetric Analysis (TGA)}

The thermobalance [4] used for thermogravimetric analysis was as shown in figure 4. It consisted of a sensitive recording balance (microbalance) combined with a means for programmed control of the sample temperature and for control of the atmosphere surrounding the sample, i.e. vacuum, air, or other gases. A close-up of the sample crucible and furnace is shown in figure 5 .

In the procedure used in this study, a sample of about $10 \mathrm{mg}$ weight, which had been cleaved from the pipe, was heated from room temperature, at a rate of $2^{\circ} \mathrm{C} / \mathrm{minute}$ to a temperature of $600^{\circ} \mathrm{C}$; the measurements were made in both vacuum and in air. The weight of the sample was recorded as a function of the temperature.

Typical results are shown in figure 6. 


\subsection{Hardiness}

A property of a material related to its resistance to deformation is its hardness. Hardness, however, is an empirical measurement and values obtained depend on the apparatus and technique used as well as the material. The standard hardness apparatus for hard plastics is the Durometer, type D. This apparatus, as normally used and described in ASTM D2240-68 [2], requires flat specimens with measurements being made at room temperature only. There is no standard test for hardness of plastic pipe [6]. Hence, an apparatus based on the standard hardness meter was developed. Figure 7 shows the basic apparatus with its V-block to support the pipe and a lever arrangement and bearing support for the gauge. Additionally, provision for circulating water at a constant temperature through the pipe allows the determination of a hardness/temperature relationship for the piping. A close-up of the hardness indentor in contact with a pipe sample is shown in figure 8.

Typical results obtained using the apparatus are summarized in Table 4. They appear to be in the range of values ( 85 to 95 Shore $D$ at room temperature) reported for rigid PVC and CPVC in Modern Plastics Encyclopedia.

\subsection{Method for Chlorine Content}

The results obtained with the TGA in air, indicating the same weight loss was obtained as in a vacuum, suggested the possibility of a new quick procedure for determining the chlorine content of PVC and CPVC plastics. This is particularly important for CPVC since the chlorine content of the raw material is variable and the physical properties depend on the chlorine content. Also, overheating of either material during processing or pipe manufacture causes loss of chlorine as HCl. Hence, low chlorine values might indicate overheated material [5].

The procedure is a simple one in which a finely cut up sample is weighed in a porcelain crucible and heated to constant weight (approximately two hours) in a furnace carefully controlled to $250^{\circ} \mathrm{C}+0^{\circ}-10^{\circ} \mathrm{C}$. The weight loss is calculated as $\% \mathrm{HCl}$ and compared to the theoretical values of $58.1 \%$ and $75.0 \%$ for PVC and CPVC respectively. Some typical results are given in Tables 5 and 6.

\subsection{Aging Studies}

\subsubsection{Weather-Ometer*}

Laboratory aging studies were carried out in a commercial apparatus called a Weather-Ometer [7]. Its interior is shown in figure 9. This apparatus is capable of cycles of simulated rain, of simulated sunlight and darkness, and limited cycles of temperature. The studies carried out on the plastic pipe ised the rain cycle and continuous sunlight only. The cycles were set for $9 \mathrm{~min}$. rain per hour to give a total of $805 \mathrm{hrs}$ light and $120 \mathrm{hrs}$ of rain during the test period. At 5 intervals, the pipe was removed and tested for change in hardness and in TMA characteristics. TGA curves were run on selected samples after the weathering was completed. Figure 10 shows samples before and after weathering.

\subsubsection{Indoor, Thermal Aging}

Although the majority of the plastic piping would not normally be exposed to exterior weathering conditions, it might well be subjected to thermal aging in the walls of a building. Hence, a thermal aging procedure was developed. Samples were measured, placed in a closely controlled oven $\left(80 \pm 0.1^{\circ} \mathrm{C}\right.$ or $\left.176 \pm 0.2^{\circ} \mathrm{F}\right)$ and held at this temperature for prolonged periods of time. Measurements of hardness, TMA, and TGA studies were made after oven aging. Figure 11 shows the samples before and after aging. Table 7 lists the observed changes in dimensions with heating.

* Certain commercial instruments are identified in this paper in order to adequately specify the experimental procedure. In no case does such identification imply recommendation or endorsement by the National Bureau of Standards, nor does it imply that equipment

identified is necessarily the best available for the purpose. 


\subsubsection{Outdoor Weathering Study}

The Weather-Ometer results discussed in section 4.4.1 indicate that outdoor weathering studies are desirable. However, since they will require long periods (over one year), they have been deferred for future work.

\section{Results}

4.1 TMA

The thermomechanical analyzer results indicate the various movements of the sample resulting from stress relaxation and flow under the thermal environment and external loading applied.

Figure 3, A and B, show the effects observed with the TMA and may be interpreted in the following manner. In figure $3 \mathrm{~A}$, for the transverse section of a $11 / 2$ " PVC DWV pipe, the pipe material expands slightly with temperature in the range from room temperature to about $79.5^{\circ} \mathrm{C}\left(175^{\circ} \mathrm{F}\right)$ at which point the material shows a small, but rapid, expansion as it undergoes its glass transition. Above $85^{\circ} \mathrm{C}\left(185^{\circ} \mathrm{F}\right)$, following completion of the glass transition, the material continues to expand in the transverse direction, at an ever increasing rate, until a temperature of about $193^{\circ} \mathrm{C}\left(380^{\circ} \mathrm{F}\right)$ is reached. In this temperature region, the material begins to flow rapidly under the weight of the probe which penetrates into it causing an apparent shrinkage. Comparing these results with the other curves in figure $3 \mathrm{~A}$, it can be seen that the material behaves quite differently in the longitudinal and circumferential directions (see figure 12). Again, normal expansion occurs up to about $75.5-82^{\circ} \mathrm{C}$ $\left(175-180^{\circ} \mathrm{F}\right)$, but then rapid contraction takes place between 82 and $88^{\circ} \mathrm{C}$ ( 180 and $190^{\circ} \mathrm{F}$ ), with a slower contraction changing to flow as the temperature is increased further. These behaviors can be explained on the basis of the previous description of the extrusion process and the properties of thermoplastic materials. PVC exhibits its glass transition at about $80^{\circ} \mathrm{C}\left(176^{\circ} \mathrm{F}\right)$ [5]. There is a little variation in this temperature with the molecular weight of the polymer. Hence, the first change in the expansion curve at $82^{\circ} \mathrm{C}\left(180^{\circ} \mathrm{F}\right)$ appears to be associated with the glass transition.

The rapid expansion above this temperature for the transverse sample may be accounted for by the spontaneous deformation of the sample as the internal molding stresses are relieved at the higher temperature. As expected, such swelling in wall thickness is accompanied by shrinkages in the longitudinal and circumferential directions. The viscosity would fall with increasing temperature allowing the stress relaxation to occur more and more rapidly until complete and/or until the viscosity is too low for the material to support the probe. The temperature at which the probe begins to sink into the transverse sample $\left(193^{\circ} \mathrm{C}\right.$ or $380^{\circ} \mathrm{F}$ ) is near the temperature used in the original extrusion process.

The results of similar experiments on CPVC piping are shown in figure 3B. The figures suggest that the glass transition for this CPVC material is in the temperature region of $110-120^{\circ} \mathrm{C}\left(230-240^{\circ} \mathrm{F}\right)$.

\subsection{TGA}

The thermal stability of a polymeric material, including a thermoplastic, is the ability of the material to withstand heating without irreversible changes in its chemical and physical properties. In this study, TGA was used to determine the ranges of thermal stability of PVC and CPVC piping. Weight loss curves were obtained both in vacuum and in air for both materials [6]. Typical results are shown for each material in figures $6 \mathrm{~A}$ and $B$.

The resulting weight losses are explained in the following manner. The weight loss behavior for both PVC and CPVC, with increasing temperature, is the same both in air and vacuum for room temperature to about $220^{\circ} \mathrm{C}\left(430^{\circ} \mathrm{F}\right)$. Both materials begin to break down thermally at about $204^{\circ} \mathrm{C}\left(400^{\circ} \mathrm{F}\right)$ liberating $\mathrm{HCl}$ [9]. The HCl comes off quantitatively until all chlorine is stripped from the molecules. This point was reached at about $315^{\circ} \mathrm{C}$ $\left(600^{\circ} \mathrm{F}\right)$ in this experiment. The remaining unsaturated hydrocarbon chains are thermally stable in vacuum to about $388^{\circ} \mathrm{C}\left(730^{\circ} \mathrm{F}\right)$ at which point they break down and boil off 
leaving a carbon residue. The carbon residue can then be burned off by introducing air to the hot sample and the final residue is mineral ash. In air, combustion takes place at temperatures above $400^{\circ} \mathrm{C}$ burning the carbonaceous residue directly to leave mineral ash [10].

This test shows that both PVC and CPVC lose $\mathrm{HCl}$ under heating to $315^{\circ} \mathrm{C} \cdot\left(600^{\circ} \mathrm{F}\right)$ and that, for PVC, this loss agrees with the theoretical complete loss of $\mathrm{HCl}$. Also, the $\mathrm{HCl}$ is evolved at temperatures well below combustion and there is little difference in the temperature dependence of the evolution of $\mathrm{HCl}$ in air or vacuum.

It is possible that this test may also be used as a test for adulteration with other. materials as the shape and magnitude of the weight loss curve would be affected by the presence of other materials. The degree of chlorination of the CPVC can also be estimated by this test as described in section 3.4 .

\subsection{Hardness}

Impact resistance is an important property of pipe materials. A related property, and one which is easier to measure and may be useful in the establishment of performance criteria is hardness. The temperature dependence of hardness may reflect the sensitivity of the material to temperature changes.

The usual hardness range for rigid PVC is 85-95 on the Shore D scale. This measurement is normally made on flat specimens prepared according to the ASTM D-2240-68 procedure. The ASTM procedure is concerned with the hardness at only one temperature, $23^{\circ} \mathrm{C}\left(73.5^{\circ} \mathrm{F}\right)$. Since the PVC and CPVC piping is likely to be subjected to hot water as well as water at room temperatures, it is important that hardness testing should include temperature as a variable. By using the apparatus described in Section 3.3 and carefully controlling the rate of contact of the hardness gage and time of readings, good reproducibility of results may be obtained. Table 4 summarizes some typical data along with the average values and standard deviations of the sets of measurements. The apparatus designed for this work gives: a 2 to 5 fold improvement over the usual precision of such measurements.

The effects of temperature on the hardness of PVC and CPVC samples are shown in figure 13. These results cover the range from room temperature to $90^{\circ} \mathrm{C}\left(194^{\circ} \mathrm{F}\right)$. The hot water was circulated through the pipe samples until the outer wall temperature of the pipe sample stabilized. The coefficient of the temperature, $T$, in the equations given in figure 13, represent the rate of change of hardness as the temperature is changed. This coefficient for different materials may be a good measure of the sensitivity to temperature of the mechanical properties of the materials. If so, the hardness test apparatus could be readily modified to be used in the field for direct hardness measurements without interrupting service.

\subsection{Aging Effects}

\subsubsection{Weather-Ometer Studies}

The PVC and CPVC piping samples exposed in the xenon arc Weather-Ometer were not uniformly irradiated by the arc. As a result, in the case of PVC, the more exposed portion (front) showed a marked change as compared to the more sheltered portion (back) of the same specimen. Hardness measurements, at two different temperatures, were made on front and back after various exposure times. The PVC showed little difference between front and back versus exposure time when measured at room temperature but, at higher temperatures, it did show a tendency for the front to decrease in hardness with exposure time. The CPVC showed a slight decrease in hardness with exposure, but there was little difference between the front and back.

Even with the short exposures given in this test, some changes in the properties of the PVC occurred. For this reason, this work should be extended to evaluate the importance of weathering on these products. 
Heating a specimen of PVC DWV in an oven at $80^{\circ} \mathrm{C}\left(176^{\circ} \mathrm{F}\right)$ for about 6 days produced remarkable changes in the appearance of the piping and in its dimensions. Table 7 shows the dimensional changes of the samples shown in figure 1l. Table 8 showed length changes of pipe sections on oven heating at $90^{\circ} \mathrm{C}\left(194^{\circ} \mathrm{F}\right)$ to determine the limit of this effect. These changes, though slight, are in the direction indicated by the TMA measurements and were not completed since further heating produced further changes. This aging phenomenon, which is believed to be due to stress relaxation, is probably the most serious potential problem in the long term use of PVC, and possibly CPVC, piping. Certainly, more needs to be learned about relating the results of laboratory studies of heat effects to long time performance in service. Proper evaluation of the thermal stability is also important to establish whether there is a slow loss of $\mathrm{HCl}$ from PVC and CPVC under prolonged moderate heating with consequent degradation of physical properties and chemical resistance of the materials $[10]$.

\section{Summary of Results}

The most important finding of this study of the effects of elevated temperatures on commercial samples of PVC and CPVC piping is the discovery of the presence of large amounts of internal stress in the PVC-DWV piping that is relieved by dimensional changes which take place at temperatures in the neighborhood of $82^{\circ} \mathrm{C}\left(180^{\circ} \mathrm{F}\right)$. This effect is critical because the temperature at which it occurs is so near the maximum hot water temperature which may be found in residential occupancies. The permanent dimensional changes which occurred in the PVC piping resulted in shorter lengths, smaller diameters, and greater wall thicknesses. While CPVC shows similar behavior, it only does so at a higher temperature, $110-120^{\circ} \mathrm{C}\left(230-248^{\circ} \mathrm{F}\right)$ which is probably enough above the maximum expected hot water temperature for little trouble to develop from this characteristic.

Hardness measurements as a function of temperature appear to be indicative of differences in temperature sensitivity of mechanical properties between PVC and CPVC and can be readily measured to sufficient precision to be considered as a quantitative measure. However, neither hardness nor its temperature coefficient have yet been directly related to a critical performance requirement.

Thermal stability, as defined by the temperature at onset of decomposition, shows little difference between PVC and CPVC; both begin to decompose at approximately $204^{\circ} \mathrm{C}$ $\left(400^{\circ} \mathrm{F}\right)$, liberating $\mathrm{HCl}$. The total weight loss appears to be quantitative for the chlorine content and may be useful as a measure of the degree of chlorination of the CPVC. The thermal decomposition appears to only take place at a sufficiently high temperature as to remove almost all concern about decomposition under normal use of PVC and CPVC in plumbing systems in homes.

Accelerated aging studies using a xenon arc Weather-Ometer showed some slight evidence of changes in properties of PVC, but the results were too scattered to allow unequivocal conclusions to be made. This study should be continued for longer periods of time to establish its significance.

\section{Future Needs of This Program}

The work reported here showed the need for long-range studies of thermoplastic materials, both for DWV and pressure distribution of hot and cold water, to provide a basis for the establishment of performance criteria. Studies related to the effects of long-term use on the critical mechanical and dimensional properties are important if predictions of expected lifetimes for the products are to be made from laboratory tests of thermal and other properties. Some potential instability of the materials to heat and light, leading to possible permanent deformation, would indicate the desirability of studies of mechanisms of change of properties with time with a view to recognizing such changes in the future. 
An area not investigated in this study is stress-corrosion. This phenomenon, which has resulted in failures of metals and plastics in other applications, is not very well understood or predictable. It, therefore, needs investigation in terms of materials, manufacturing processes, assembly parameters, and environment. A careful survey of problems in the industry should be made and kept up-to-date to allow the most rapid response to problems before they become major issues of concern. 
$\underline{\text { Term }}$

1. Coefficient of Expansion

2. Glass Transition

3. Glass Transition Temperature $(\mathrm{Tg})$

4. Hardness

5. Polymer

6. Softening Point

7. Thermoplastic

8. Viscosity
Definition

the fractional expansion per degree rise of temperature

the reversible change in an amorphous polymer, or in amorphous regions of a partially crystalline polymer, from (or to) a viscous or rubbery condition to (or from) a hard, relatively brittle one.

the approximate midpoint of the temperature range over which the glass transition takes place.

the resistance of a plastic material to compression and indentation.

a compound formed by the reaction of simple molecules having functional groups that permit their combination to proceed to high molecular weights under suitable conditions.

the range of temperature over which a plastic changes from a rigid to a soft state.

a plastic which is capable of being repeatedly softened by increase of temperature and hardened by decrease of temperature.

the property of resistance to flow exhibited within the body of a material.
Reference

[2] ASTM D883-72a

[2] ASTM

D883-72a

[12]

[2] ASTM D883-72a 
Table 2 - Thermoplastic Pipe Materials Studied

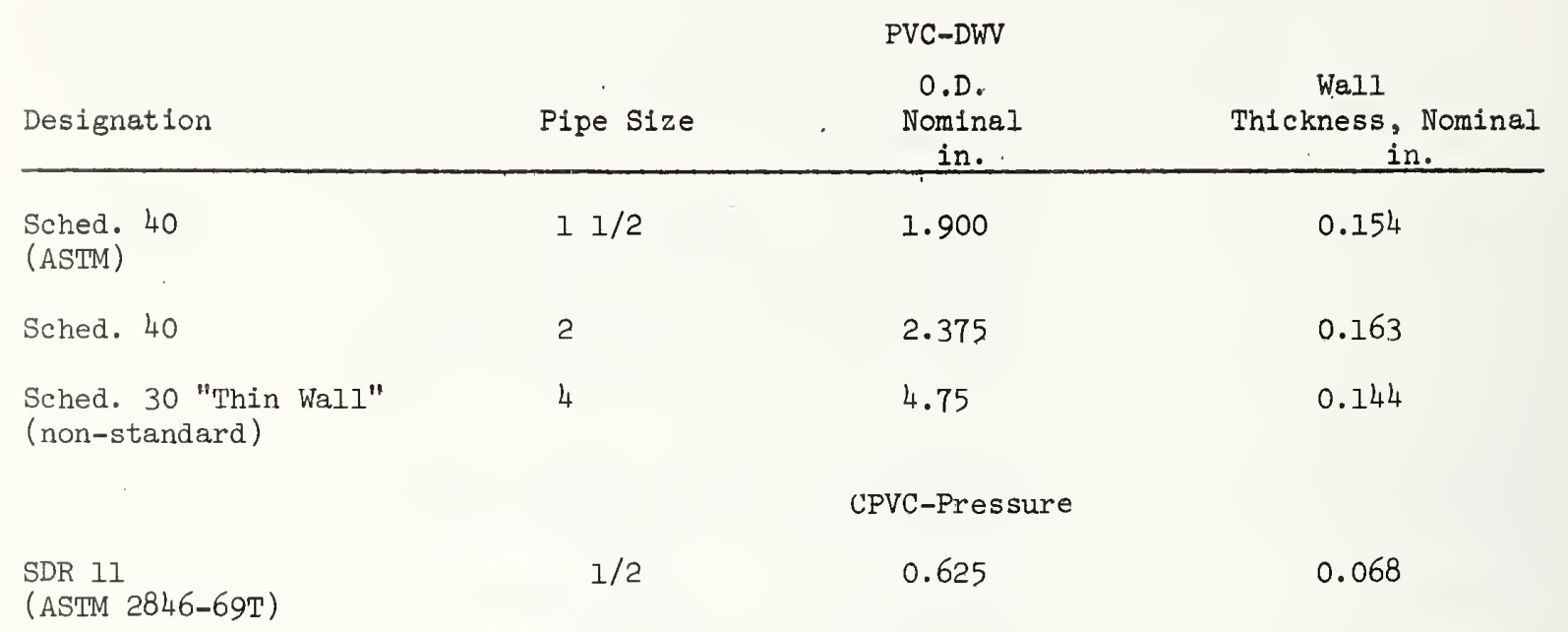


$\underline{\text { PVC }}$

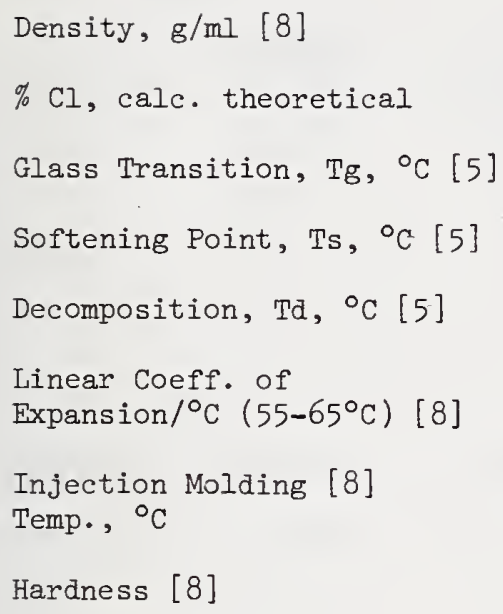

$\begin{array}{lc}1.35-1.45 & 1.45-1.58 \\ 56.5 & 72.9 \\ 80\left(176^{\circ} \mathrm{F}\right) & -- \\ 80\left(176^{\circ} \mathrm{F}\right) & 170\left(338^{\circ} \mathrm{F}\right) \\ 170\left(338^{\circ} \mathrm{F}\right) & 6.8-7.6 \times 10^{-5} \\ 5.0-18.5 \times 10^{-5} & 190-218 \\ 150-210 & \left(374-424^{\circ} \mathrm{F}\right) \\ \left(302-410^{\circ} \mathrm{F}\right) & 117-122 \text { Rockwell } \\ 65-85 \text { Shore D } & \end{array}$

Note: The sources of this information are indicated by the numbers in brackets. 


$$
\begin{gathered}
\text { Table } 4 \text { - Change in Hardness (Shore D) of PVC } \\
\text { and CPVC Piping with Temperature }
\end{gathered}
$$

a) $11 / 2^{\prime \prime}$ PVC-DWV

$\begin{array}{lccccrr}\text { Temperature* } & \begin{array}{c}26^{\circ} \mathrm{C} \\ \left(78.8^{\circ} \mathrm{F}\right)\end{array} & \begin{array}{c}38^{\circ} \mathrm{C} \\ \left(100.4{ }^{\circ} \mathrm{F}\right)\end{array} & \begin{array}{c}45^{\circ} .5^{\circ} \mathrm{C} \\ \left(113.9^{\circ} \mathrm{F}\right)\end{array} & \begin{array}{c}52^{\circ} \mathrm{C} \\ \left(125.6^{\circ} \mathrm{F}\right)\end{array} & \begin{array}{c}58^{\circ} \mathrm{C} \\ \left(136.4^{\circ} \mathrm{F}\right)\end{array} & \begin{array}{c}65^{\circ} \mathrm{C} \\ \left(149^{\circ} \mathrm{F}\right)\end{array} \\ \begin{array}{l}\text { Av. of 10 } \\ \text { measurements }\end{array} & 85.73 & 84.85 & 83.13 & 82.28 & 80.94 & 79.97 \\ \text { Std. Dev. } & 0.30 & 0.16 & 0.27 & 0.43 & 0.26 & 0.41\end{array}$

Av. Std. Dev.

0.30

\begin{tabular}{|c|c|c|c|c|c|c|}
\hline Temperature* & $\left(78.8^{\circ} \mathrm{F}\right)$ & $\left(100.4^{\circ} \mathrm{F}\right)$ & $\left(114.8^{\circ} \mathrm{F}\right)$ & $\left(130.6^{\circ} \mathrm{F}\right)$ & $\left(143.6^{\circ} \mathrm{F}\right)$ & $\left(158^{\circ} \mathrm{F}\right)$ \\
\hline $\mathrm{Av}$. of 10 & 85.97 & 84.94 & 84.58 & 84.01 & 82.48 & 81.56 \\
\hline Sta. Dev. & 0.15 & 0.08 & 0.30 & 0.09 & 0.27 & 0.33 \\
\hline
\end{tabular}

b) $1 / 2$ " CPVC-Pressure Thubing

Av. Sta. Dev.

0.20

* Surface Temperature of Pipe Sample 
Table 5 - Weight Loss Study for HCL Content of PVC

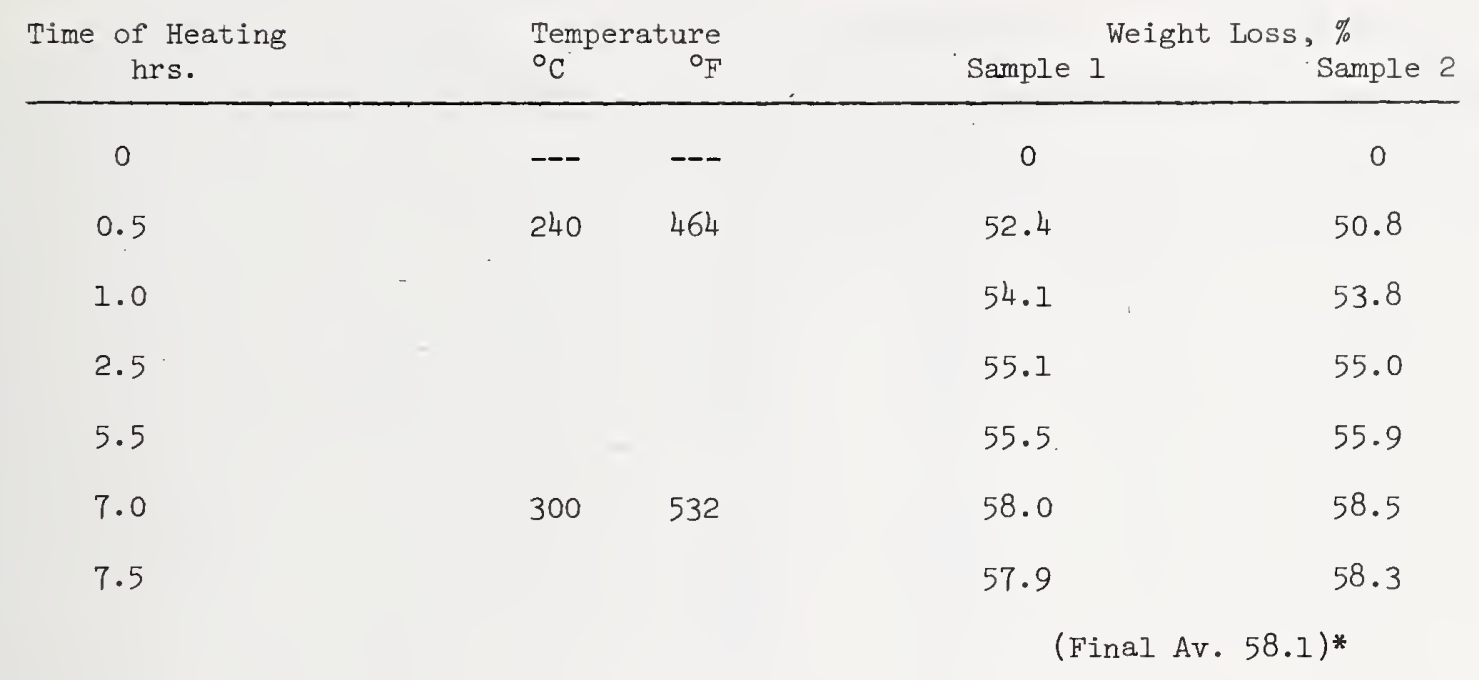

*Theoretical HCl Content, 58.1\% 
Table 6 - Welght Loss Study for

$\mathrm{HCI}$ Content of CPVC

\begin{tabular}{|c|c|c|c|}
\hline $\begin{array}{l}\text { Time of Heating } \\
\text { hrs. }\end{array}$ & $\begin{array}{l}\text { Temperature } \\
{ }^{\circ} \mathrm{C}{ }^{\circ} \mathrm{F}\end{array}$ & $\begin{array}{l}\text { Weight Loss, } \\
\text { Sample } 1\end{array}$ & $\begin{array}{l}\% \\
\text { Sample } 2\end{array}$ \\
\hline 0 & -- & 0 & 0 \\
\hline 0.5 & 280 & 63.1 & 60.2 \\
\hline 1.0 & & 63.1 & 62.0 \\
\hline 1.5 & & 62.7 & 62.3 \\
\hline 2.0 & & 65.0 & 64.2 \\
\hline 4.0 & . & 65.4 & 65.5 \\
\hline 7.0 & & 65.5 & 65.3 \\
\hline
\end{tabular}

* Theoretical HCl content for CPVC of one $\mathrm{Cl}$ per carbon atom would be $75.0 \%$. Therefore, the results above correspond to $87 \%$ of theoretical chlorination of PVC to CPVC. 
Table 7 - Dimensional Changes of PVC-DWV

Piping on Thermal Aging at

$80^{\circ} \mathrm{C}\left(176^{\circ} \mathrm{F}\right)$

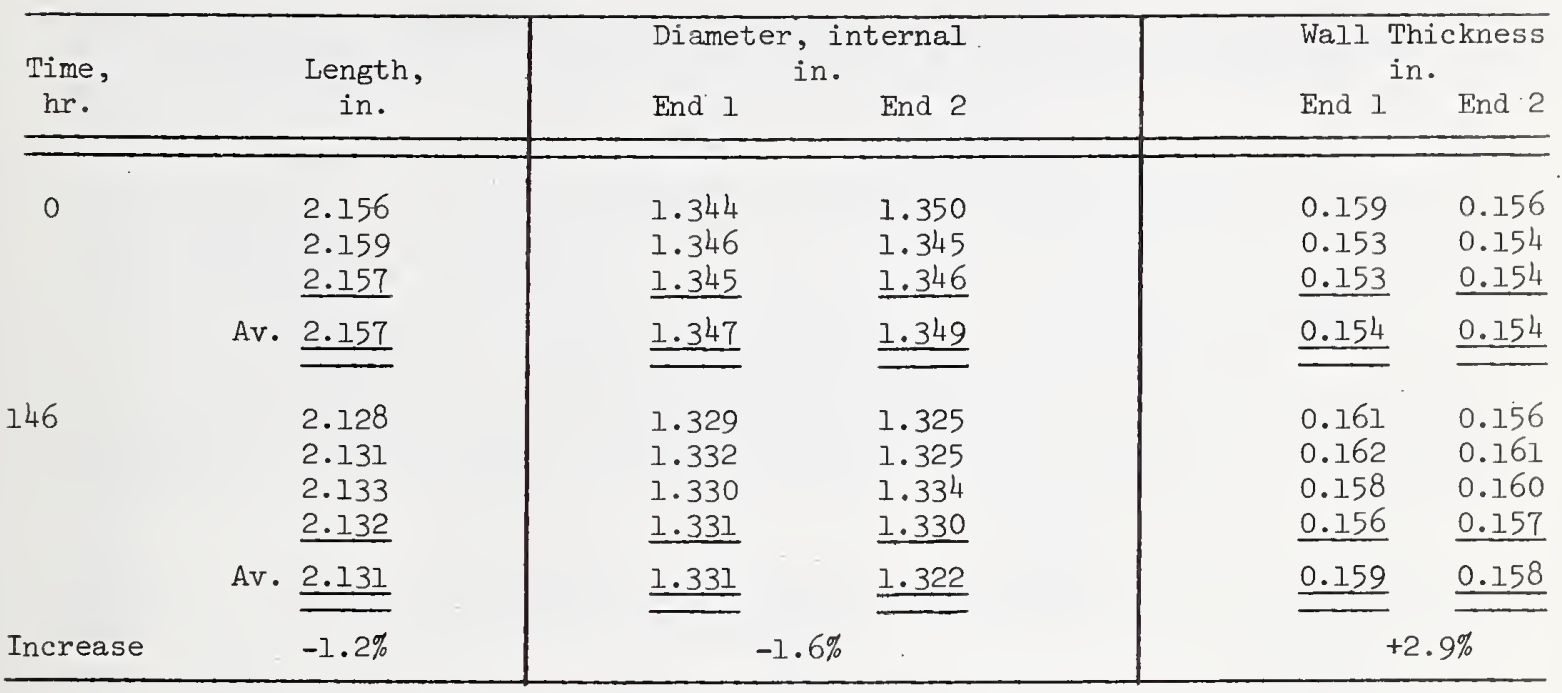


Table 8 - Decreases in Length $(\Delta L)$ of P1ping on Heating to $90^{\circ} \mathrm{C}\left(194^{\circ} \mathrm{F}\right)$

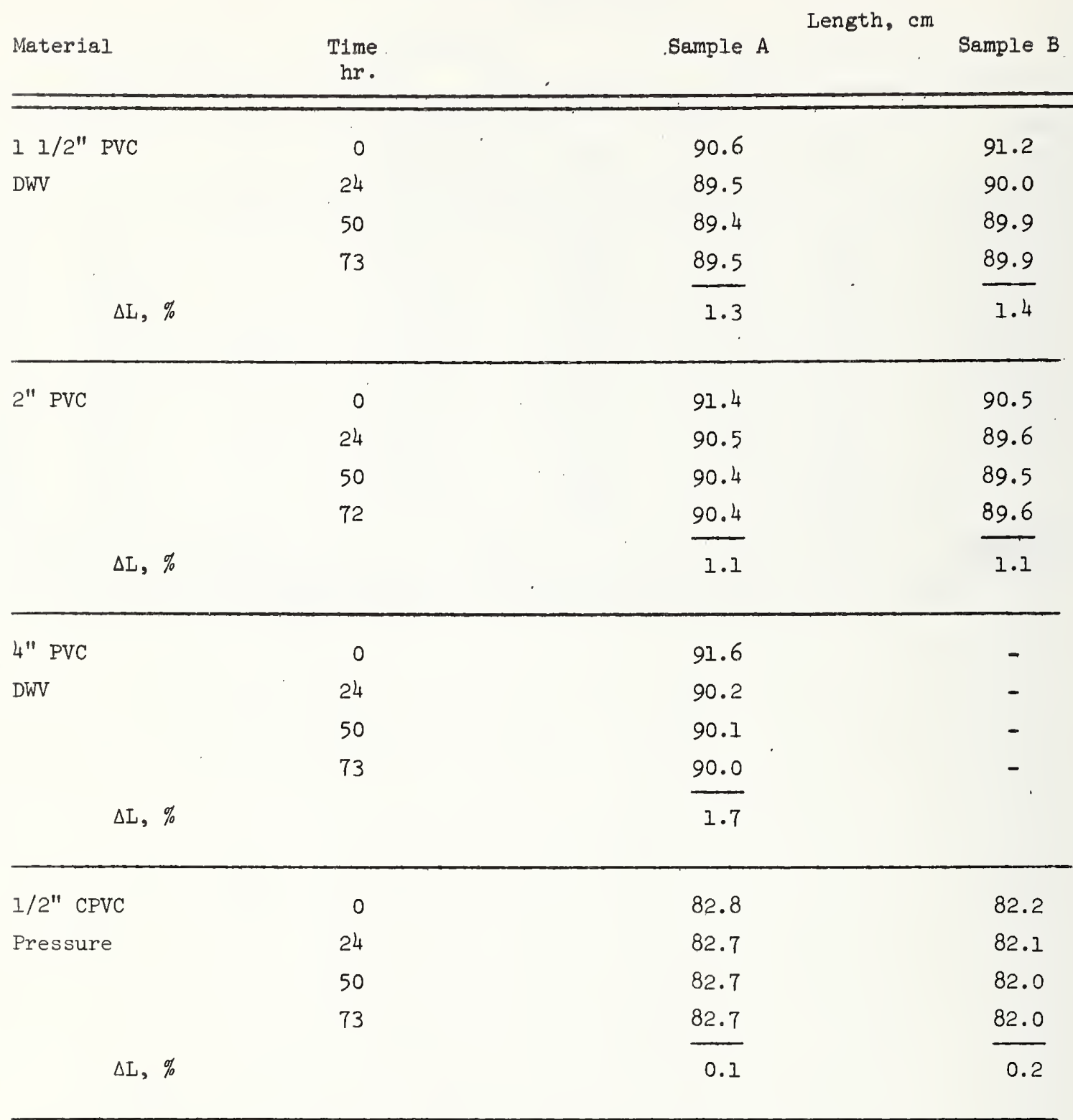


1. National Sanitation Foundation Standards, Standard No. 14. Published by National Sanitation Foundation, Ann Arbor, Michigan, October (1965).

2. 1972 Annual Book of ASTM Standards, Parts'26 and 27, Plastics-Specifications; Methods of Testing Pipe; Film; Reinforced and Cellular Plastics; Fiber Composites. Published by American Society for Testing and Materials, 1916 Race Street, Philadelphia, Peñnsylvania 19103.

3. In'struction Manual, 900 Thermal Analyzer and Modules, Section 11 - 941 TMA and Accessories, E. I. Du Pont de Nemours and Co., Inc. Instrument Products Division, Wilmington, Delaware 19898.

4. Thermoanalytical Methods of Investigation by Paul D. Garn. Published by Academic Press Inc., 111 Fifth Ave., New York, N. Y. 10003 (1965).

5. The Chemical Structure and Thermal Characteristics of Polymbers by V. V. Korshak, translated by J. Schmorak. Published by Israel Program for Scientific Translations, Jerusalem (1971).

6. Handbook of Plastics Test Methods, by G. C. Ives, J. A. Mead and M. M. Riley. Published by The Chemical Rubber Company, 18901 Cranwood Parkway, Cleveland, Ohio 44128 (1971).

7. Atlas Fade-Ometer and Weather-Ometer, Atlas Electric Devices Company, $4114 \mathrm{~N}$. Ravenswood Ave., Chicago, Illinois 60613.

8. Modern Plastics Encyclopedia, Volume 47, No. 10A, October 1970. Published by McGraw-Hill, Inc., 330 W. 42nd St., New York, N. Y.

9. Analytical Chemistry of Polymers, Ed. by Gordon M. Kline, Volume XII of High Polymers Series. Published by Interscience Publishers, Inc., 250 Fifth Ave., New York, N. Y. (1959).

10. Autoxidation and Antioxidants, Volume I and II, Ed. by W. O. Lundbęrg. Published by Interscience Publishers, Inc., 250 Fifth Ave., New York, N. Y. (1962).

11. Literature Survey on Thermal Degradation, Thermal 0xidation, and Thermal Analysis of High Polymers, PLASTEC Note 7, by David W. Levi, Picatinny Arsenal. Available from Defense Documentation Center (DDC), Cameron Station, Arlington, Va. 22314.

12. A Glossary of Plastics Piping Terms, Tech. Rpt. PPI-TRI-Nov. 1968, Plastics Pipe Institute, 250 Park Ave., New York, N. Y. 10017.

13. Chambers Technical Dictionary, 3rd Edition, The MacMillan Company, New York, N. Y.

14. Fire Endurance Tests on Wałls and Plumbing Chases Containing Either Metallic or Non-metallic Drain, Waste, and Vent Systems. W. J. Parker, NBSIR 74-449, National Bureau of Standards. 


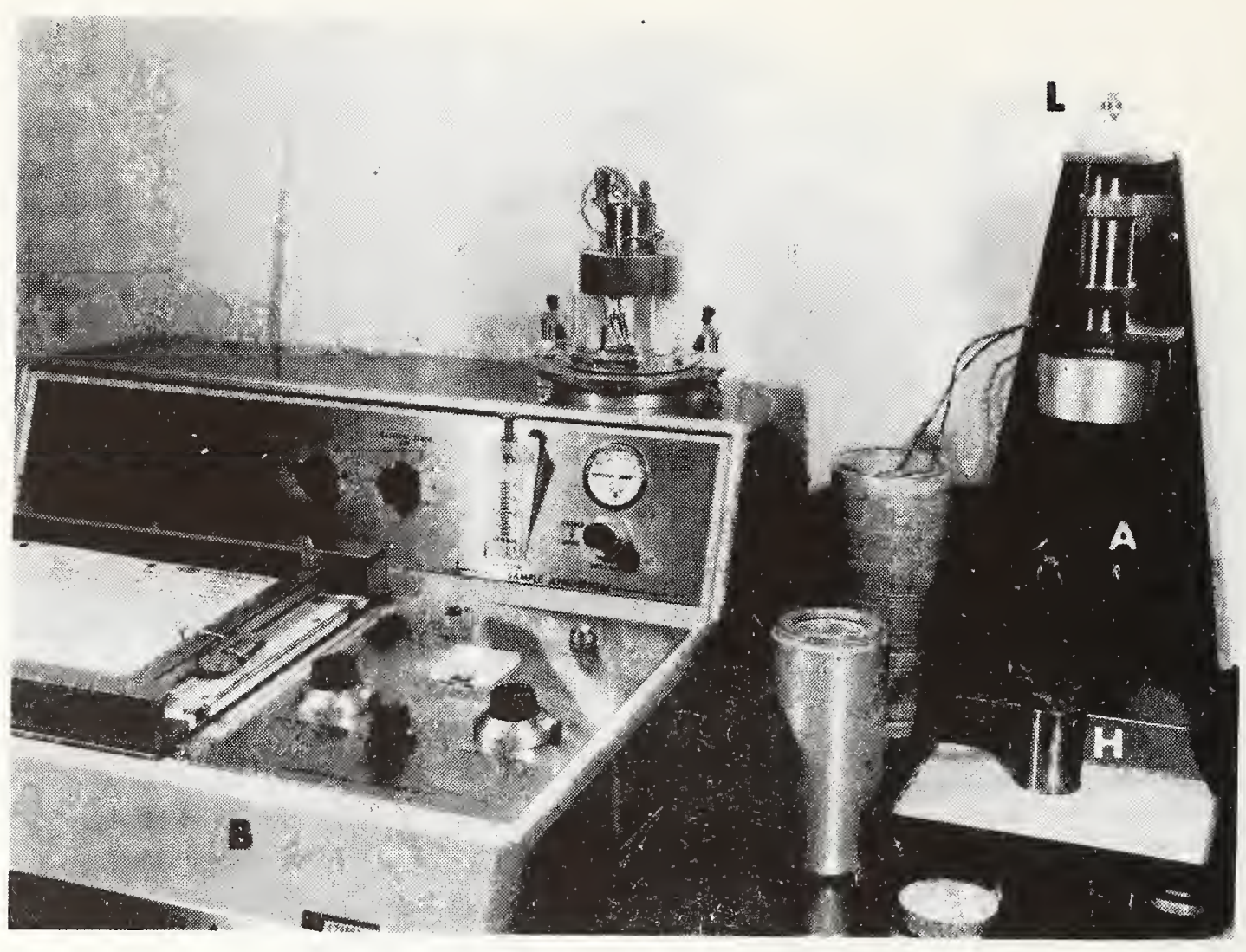

Fig. I Thermomechanical Analyzer (TMA)

$$
\begin{aligned}
& \text { A - sample area and probe } \\
& \text { B - recorder and controls } \\
& \text { H - heater } \\
& \text { L - load }
\end{aligned}
$$




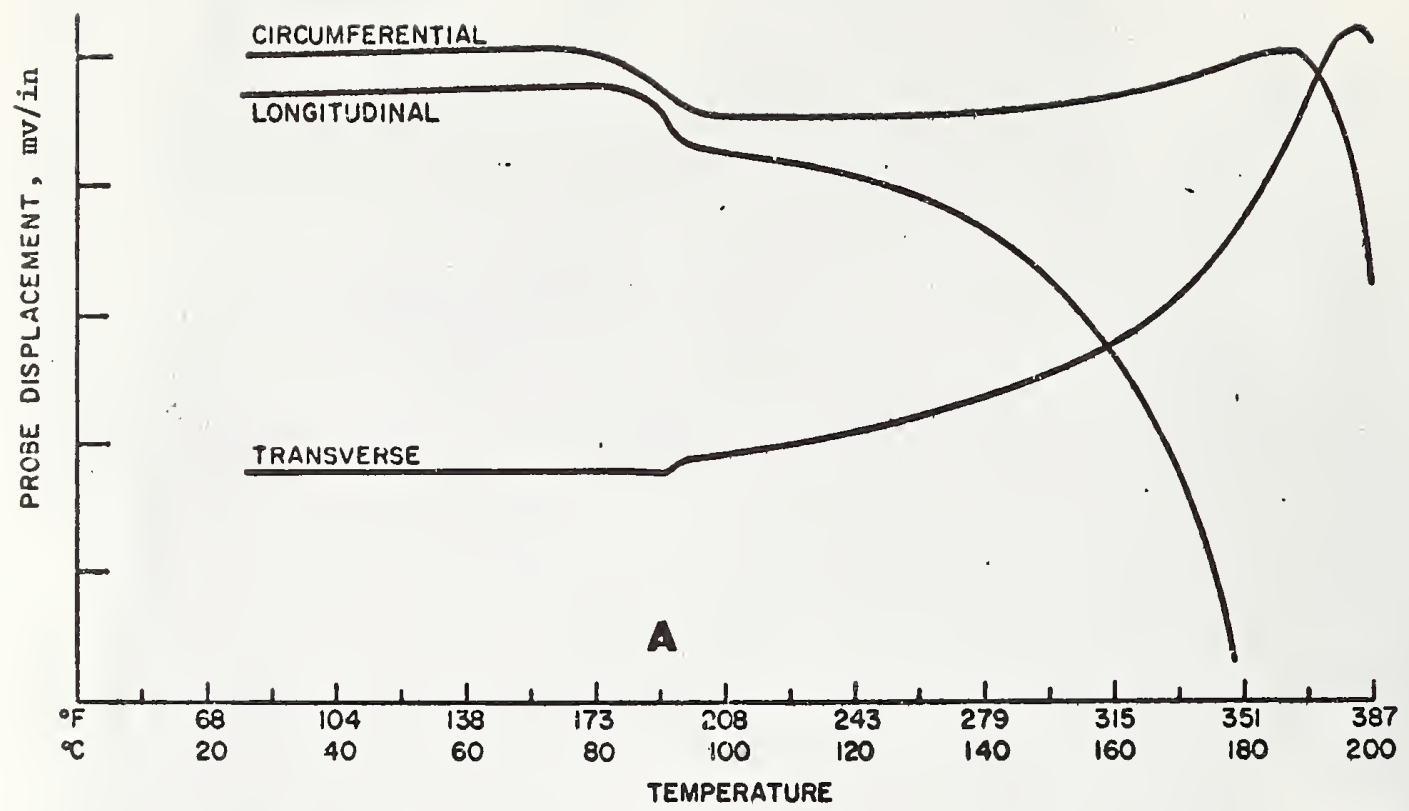

Fig. 3 TMA Curves on Pipe Samples

A - PVC DWV Pipe

Measurements made on three samples according to orientations

shown in flgure 12. Conditions of test: 10g. load on ball

tip probe, heating rate $10^{\circ} \mathrm{c} / \mathrm{min}$. starting at room temperature

in air, the probe displacement scale is $0.2 \mathrm{mV} / \mathrm{in}$. or $6.8 \mathrm{mils} / \mathrm{inch}$ of chart. 


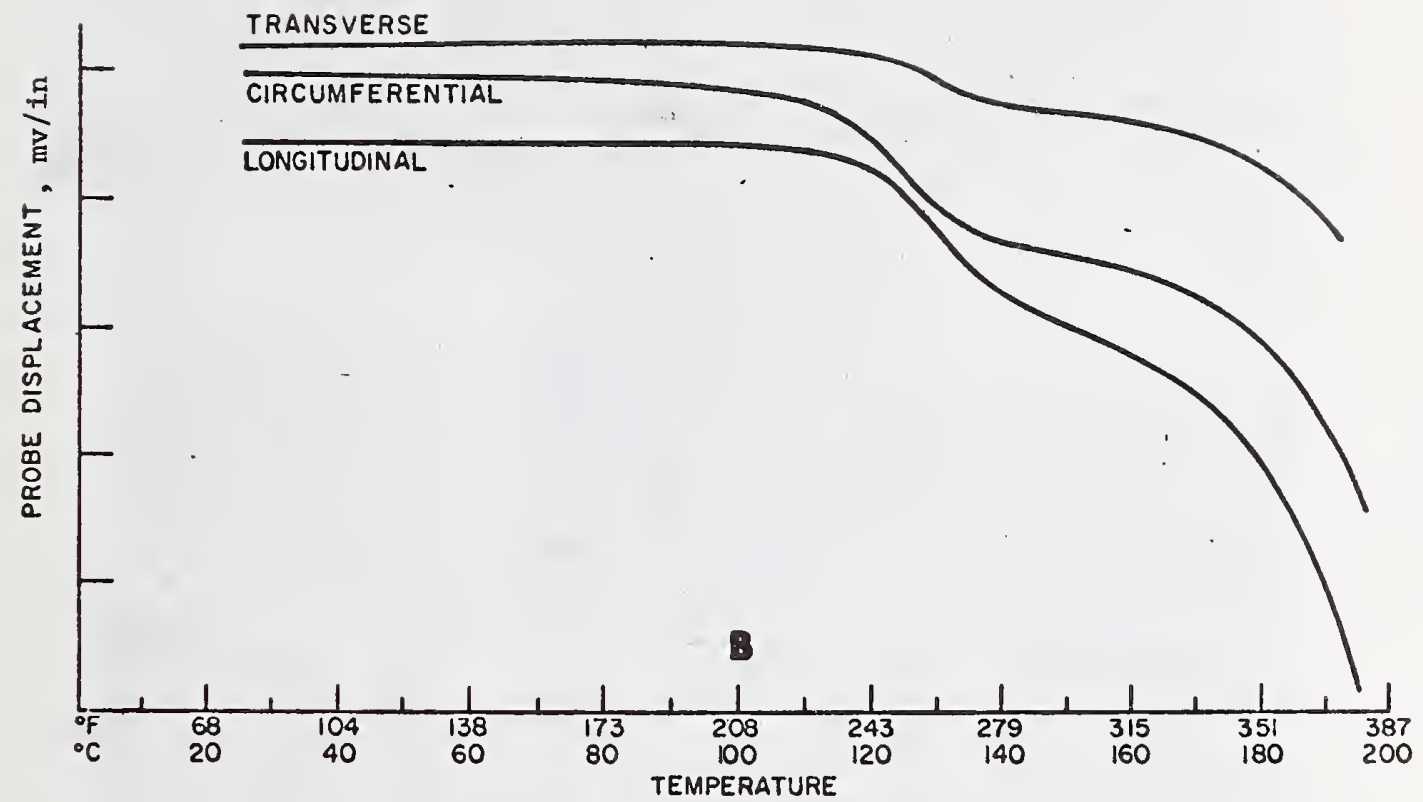

Figure 3 TMA Curves on Pipe Samples

$$
\text { B - CPVC Pressure Pipe }
$$

Measurements made on three samples according to orientations shown in figure 12. Conditions of test same as for A. 


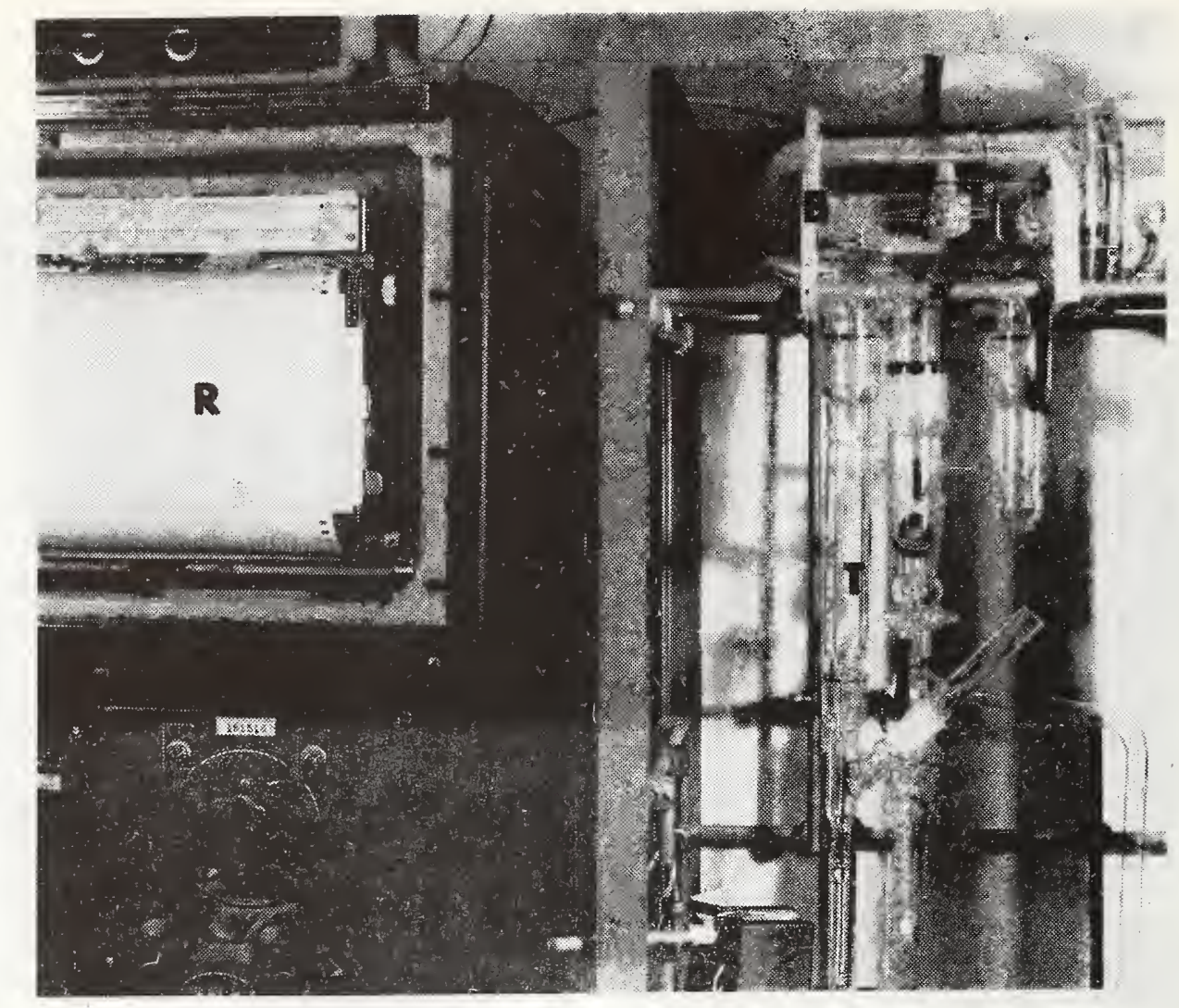

\section{Figure 4 Thermogravimetric Analysis Apparatus (TGA)}

B - microbalance

$T$ - sample chamber

$R$ - recorder 


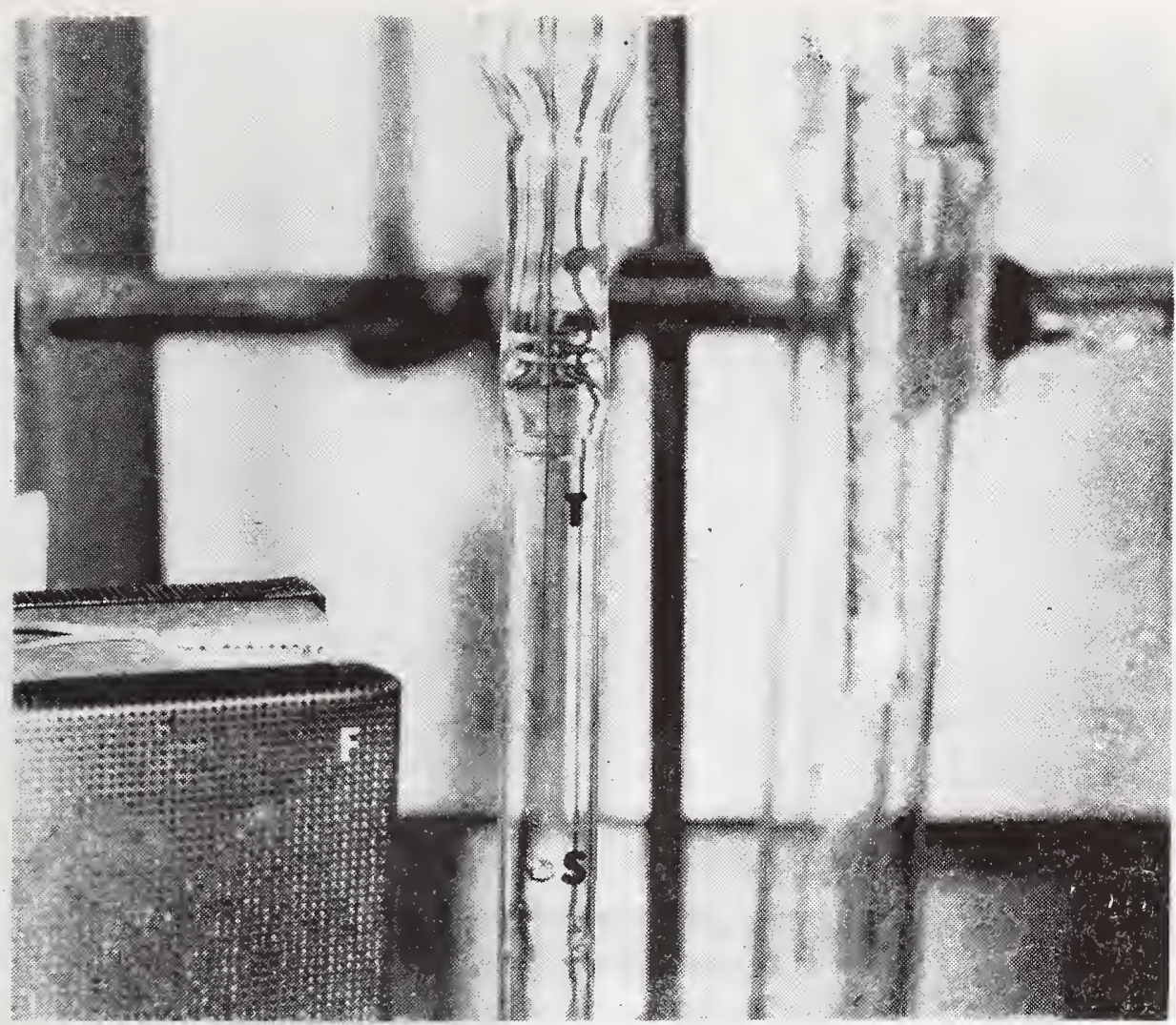

Fig. 5 Thermogravimetric Analyzer (Detail)

Close-up of sample crucible, sample chamber, and furnace.

$S$ - sample in platinum boat

$T$ - sample chamber

$F$ - furnace 


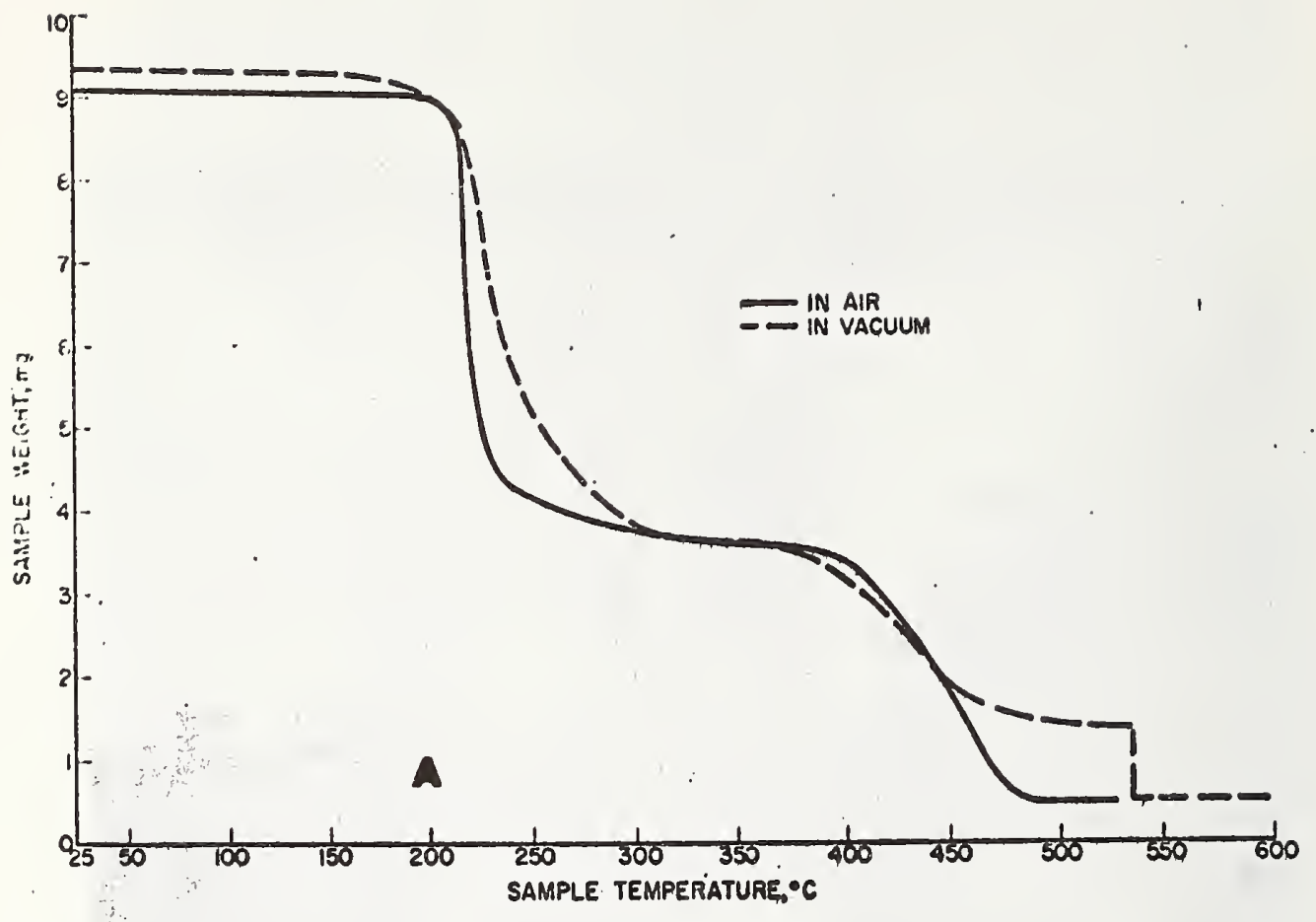

Fog. 6 TGA Curves on Pipe Samples
A - Measurements on PVC DWV in air and in vacuum as indicated. Heating rate $2^{\circ} \mathrm{C} / \mathrm{min}$, for both curves. 


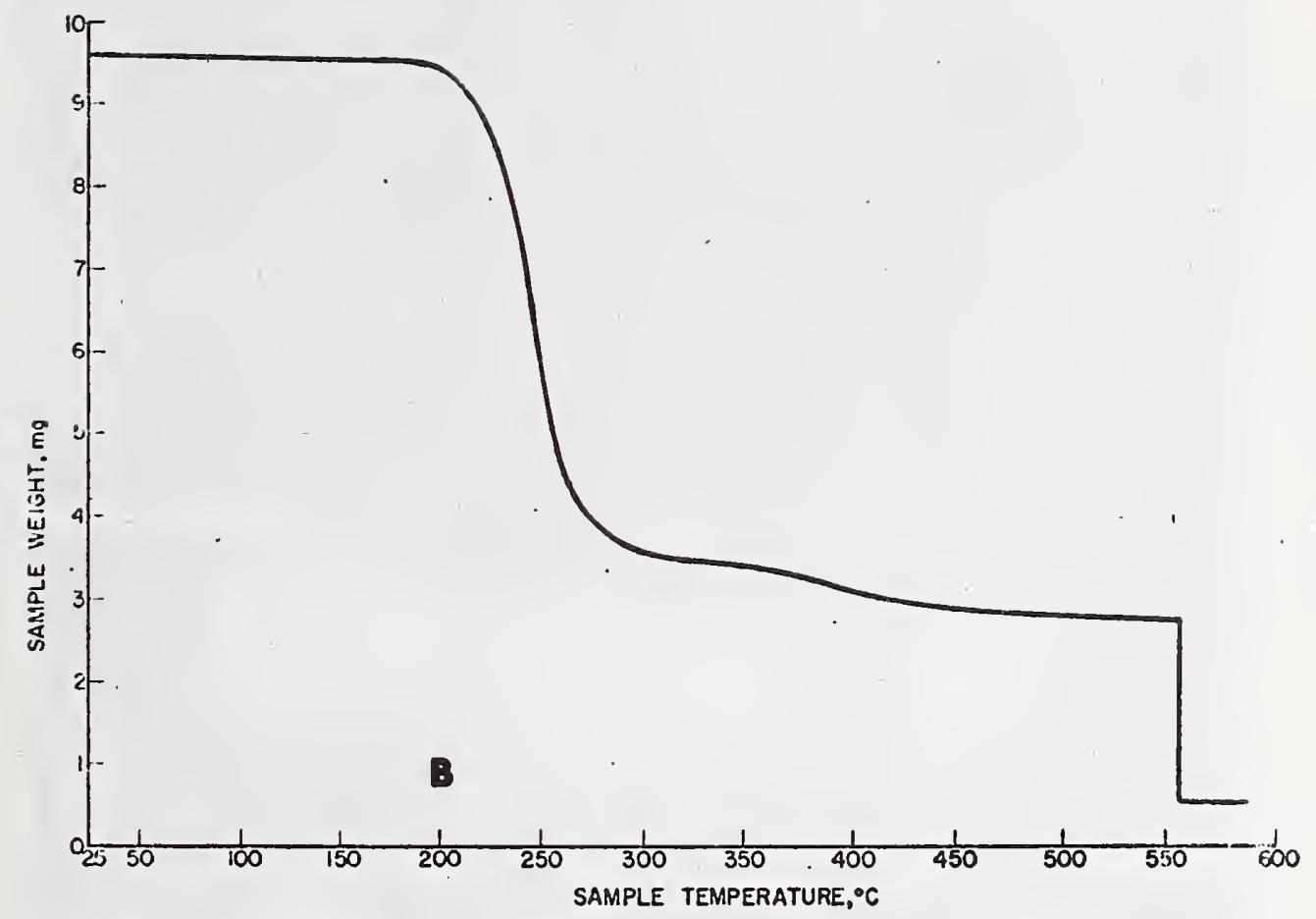

Fig. 6 TGA Curves on Pipe Samples

B - Measurements on CPVC pressure pipe in vacuum. Heating rate same as above. Similar curve obtained in air. 


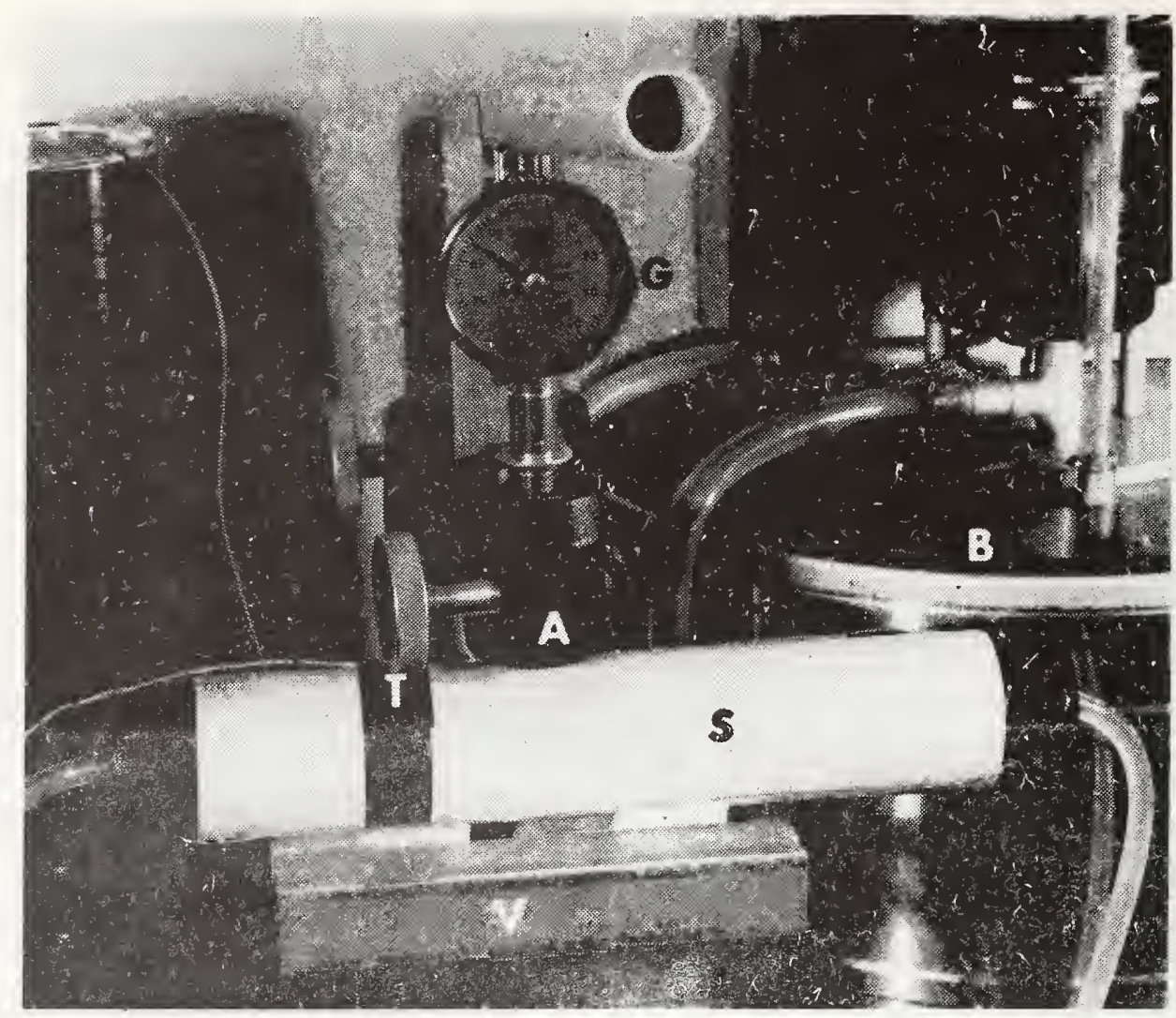

Fig. 7 Hardness Apparatus

S - sample

T - thermocouple

$\mathrm{V}$ - support block

A - hardness gage support arm

G - hardness gage

$B$ - circulating constant temperature bath 


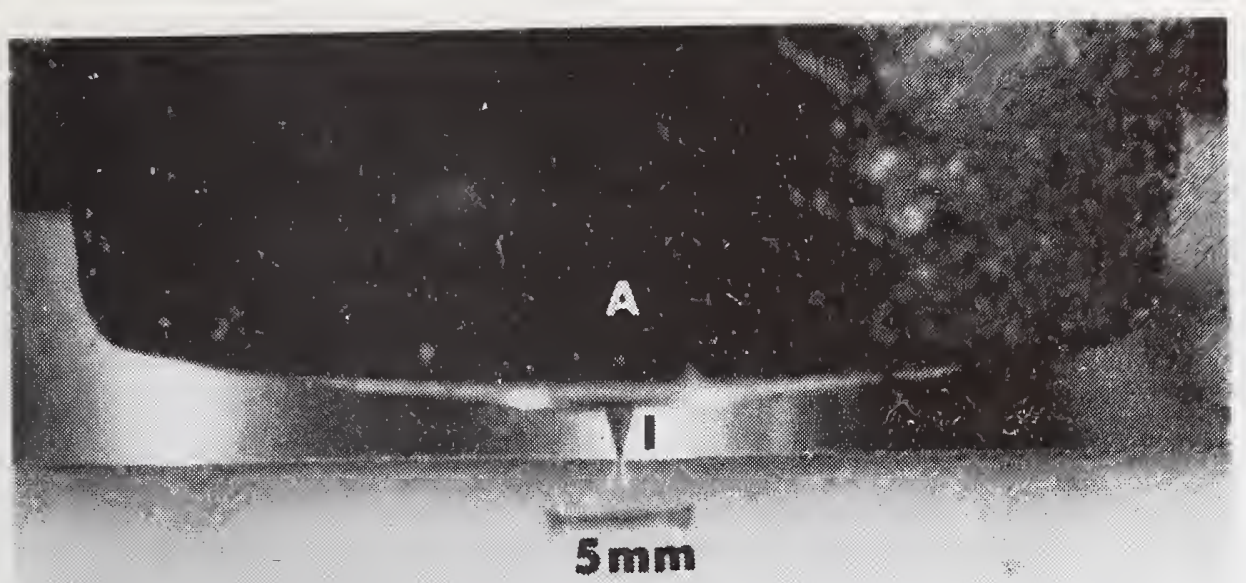

$\mathbf{s}$

Fig. 8 Hardness Apparatus (Detail)

Close-up of hardness indentor before application of test. Mark on pipe sample represents $5 \mathrm{~mm}$ (approx. 0.2 inch).

S - sample

I - indentor of hardness gage

A - hardness gage support arm 


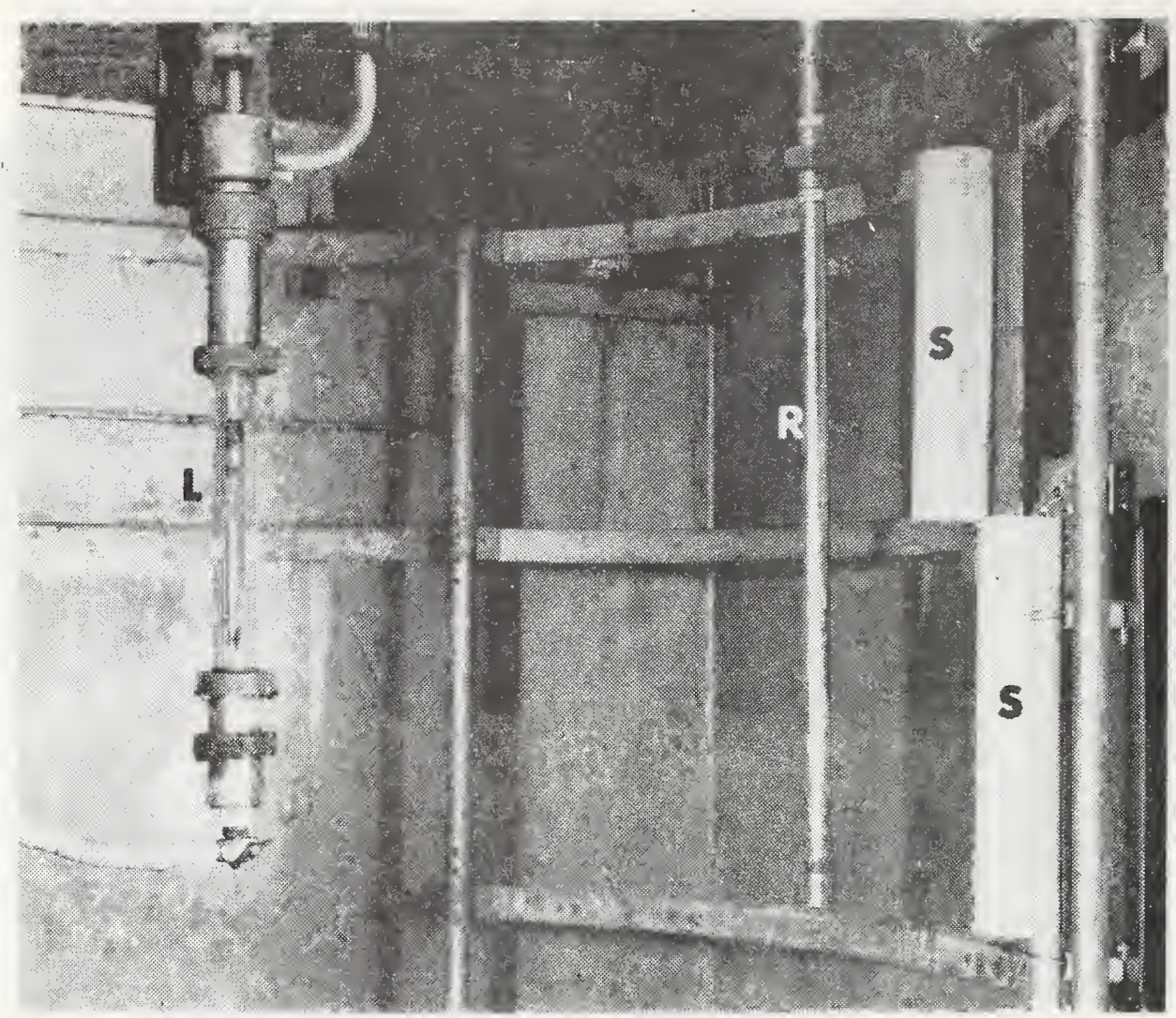

Fig. 9 Weathering Apparatus - Interior
S - sample
I - xenon arc lamp
$R$ - rain simulator (water spray) 

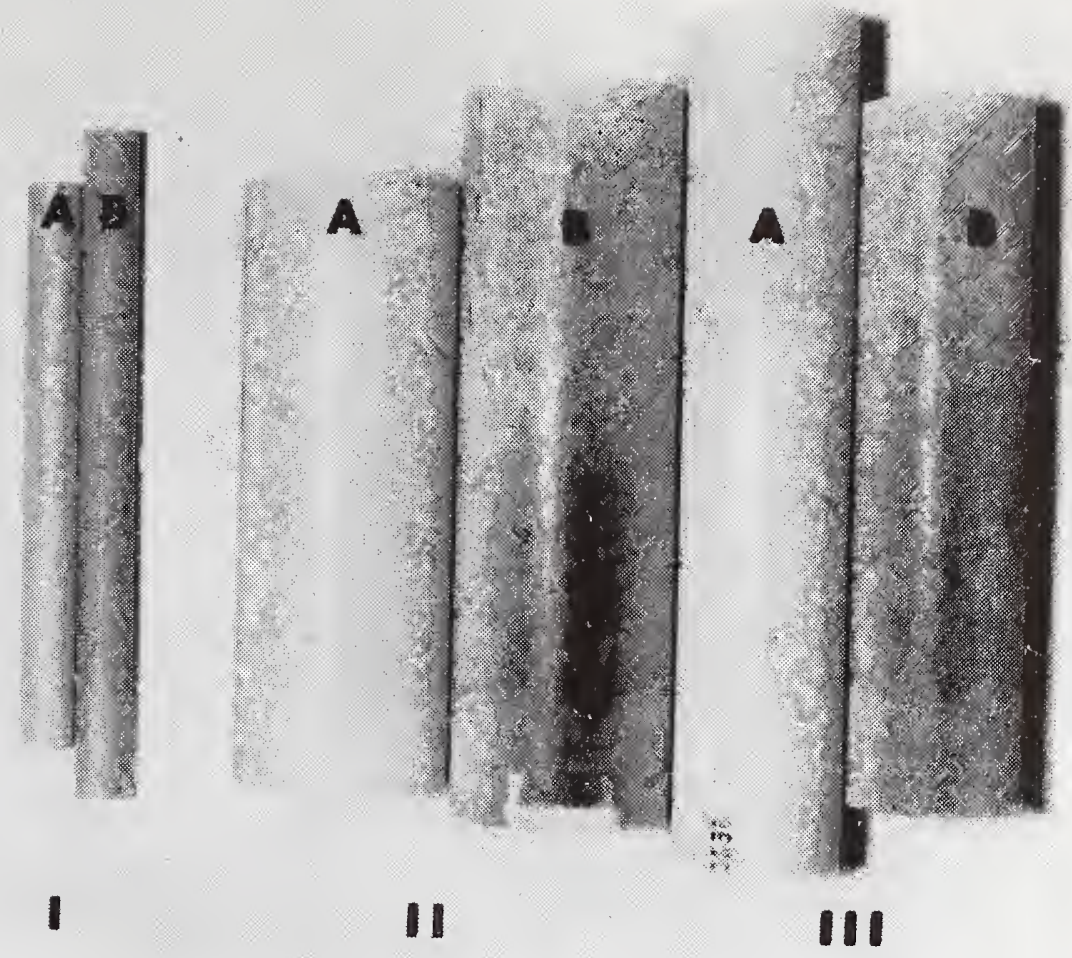


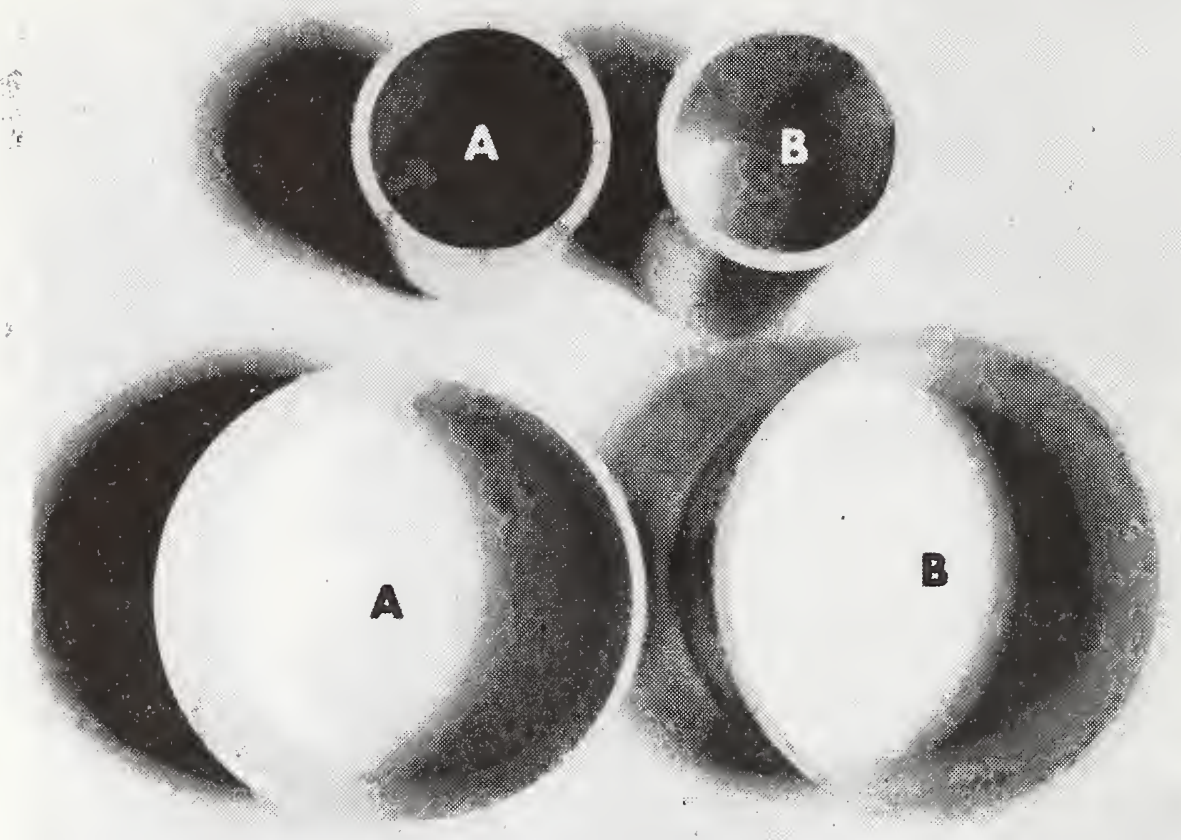

B - after heating

Upper sections are $11 / 2$ " pipe

Lower sections are 4" pipe 

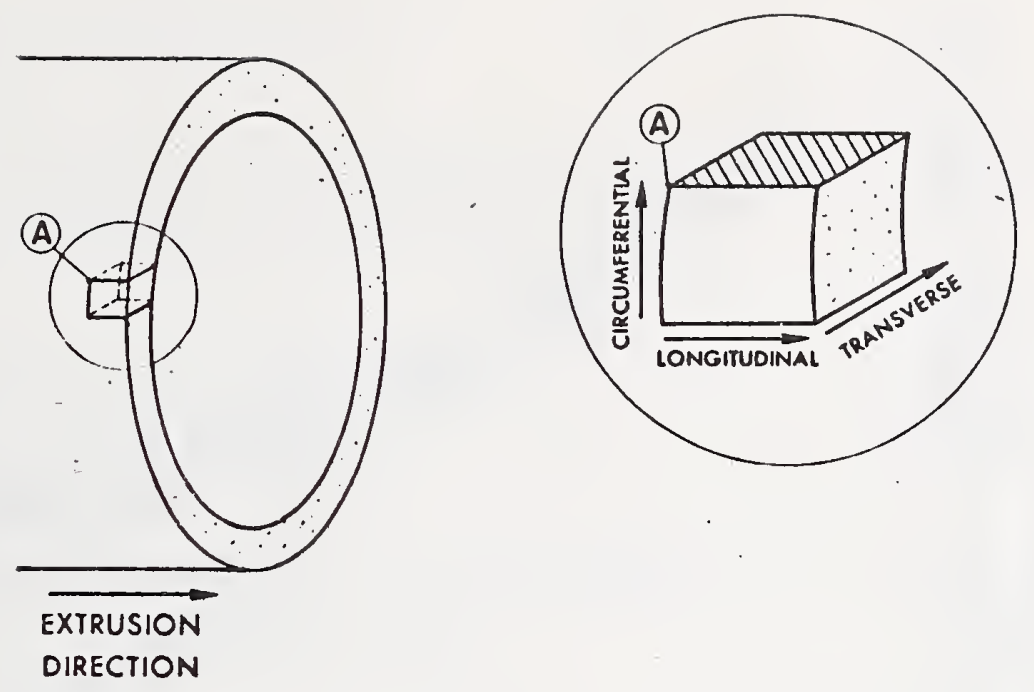

Fig. 12 Orientation of Pipe Material

Section A shows sample cut for TMA with three directions of interest for measurement of thermal movements. 


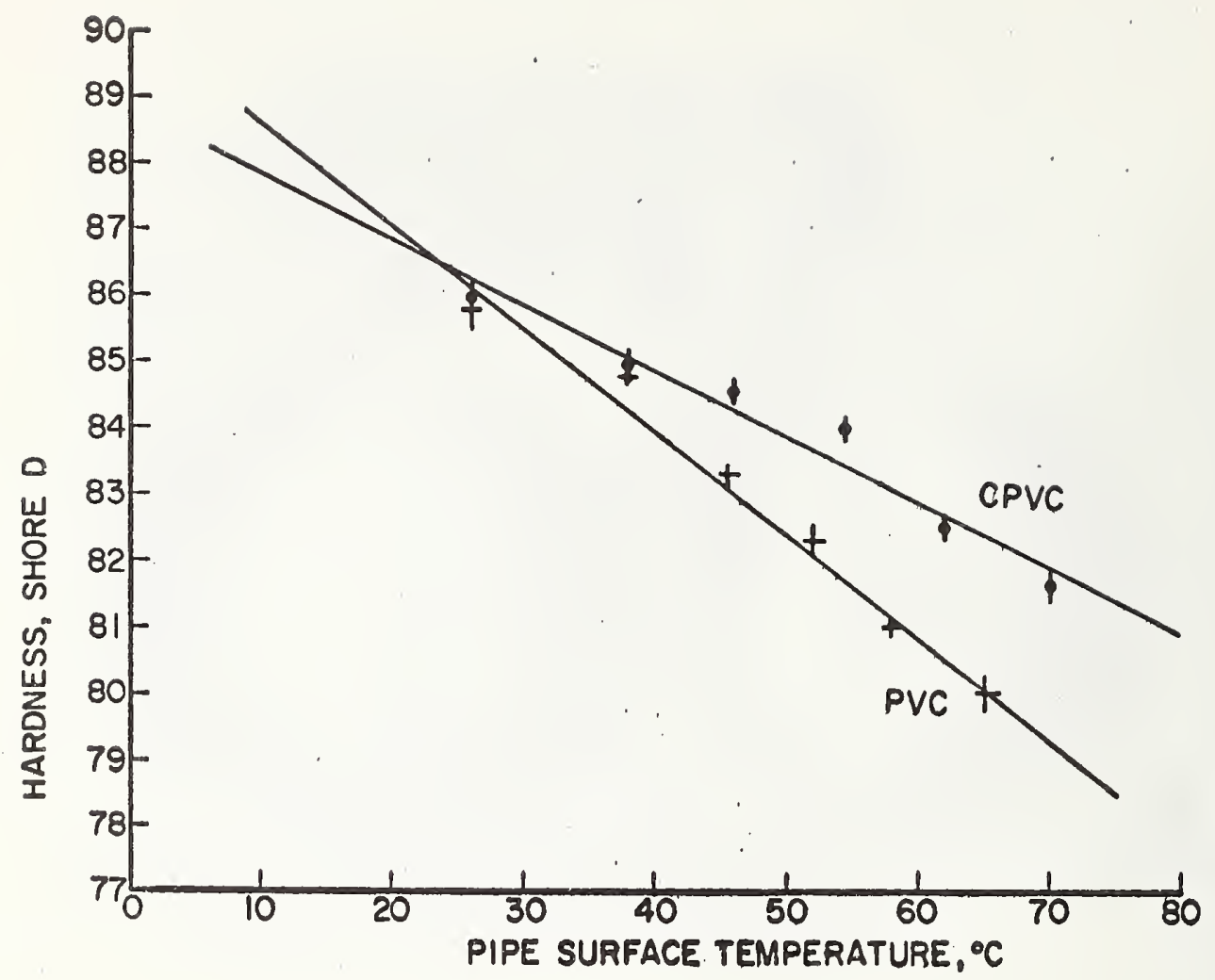

Fig. 13 Hardness as a Function of Temperature

† - PVC DWV pipe

Vertical bars indicate \pm 1 standard deviation for each point. Each point is average of 15 measurements. The regression equation for the data is: $H=-.155 \mathrm{~T}+90.13$ with correlation coefficient of 0.990 and where $H$ is the hardness, (Shore $\mathrm{D}$ ), and $\mathrm{T}$ is the temperature, $\left({ }^{\circ} \mathrm{C}\right)$.

$\phi$ - CPVC pressure pipe

Vertical bars indicate \pm 1 standard deviation for each point. Each point is the average of 15 measurements. The regression equation for the data is: H $--0.099 \mathrm{~T}+88.80$ with a correlation coefficient of 0.974 . 
NBS.114A 1.7Е

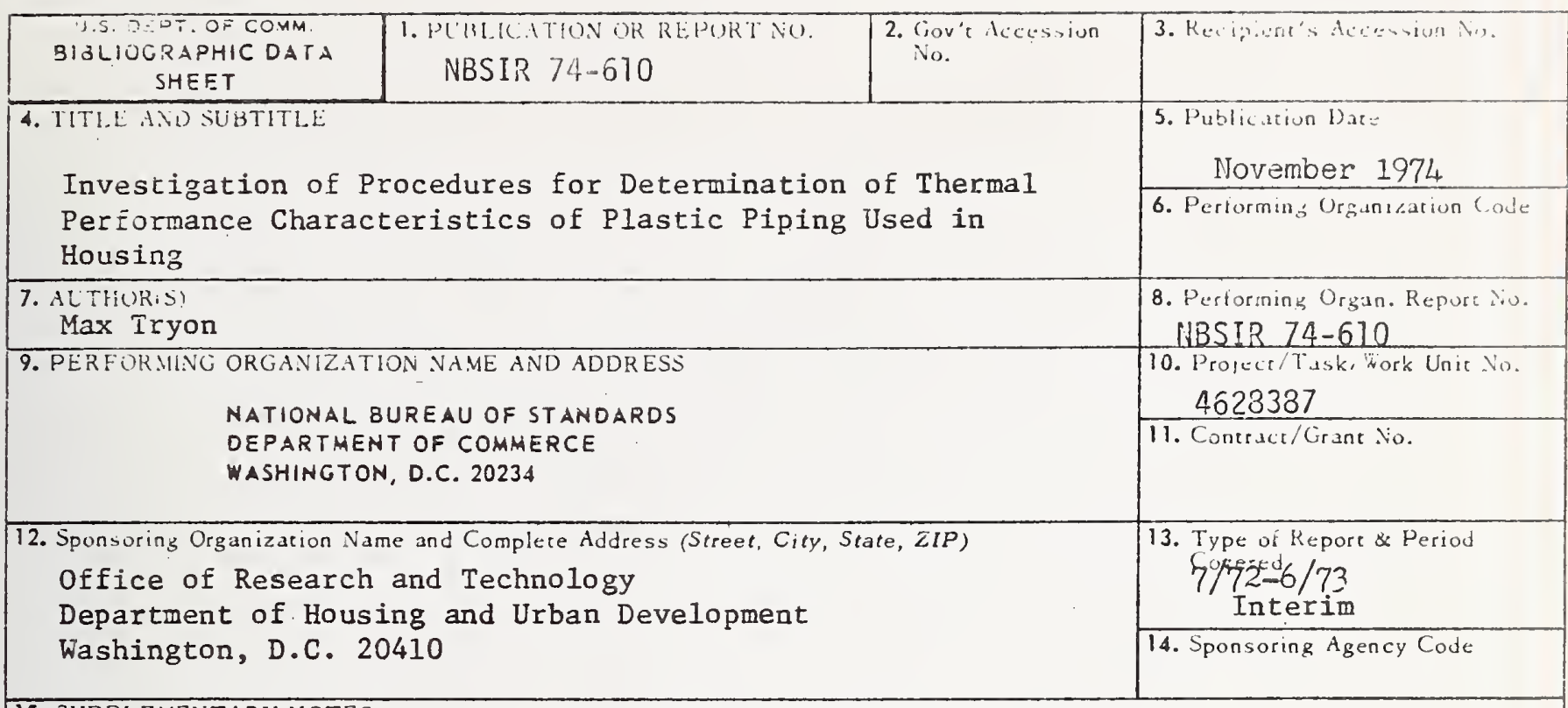

15. SLPPLEMENTARY NOTES

16. ABSTRACT (A 200-word or less factual summary of most significant information. If document includes a significant bibliography or literature survey, mention it here.)

The rapid growth of the use of thermoplastic pipe for plumbing in housing has prompted a study to determine the critical factors affecting the performance of the pipe materials. The emphasis in this preliminary study is on thermal properties such as the softening point, relaxation of thermal stress, glass transition temperature, hardness-temperature relationship, and decomposition temperature. The techniques used were thermal mechanical analysis (TMA), thermogravimetric analysis (TGA), and hardness. Preliminary results obtained on several pipe samples of PVC and CPVC commercial samples are reported.

17. KEY WORDS (six to twelve entries; alphabetical order; capitalize only the first letter of the first key word unless a oroper name; separated by semicolons)

Chlorinated polyvinyl chloride; hardness; internal stress; polyvinyl chloride; thergogravimetric analysis (TGA); thermal mechanical analysis (TMA); thermoplastic pipe; thermal properties.

18. AVALABILITY X Unlimiced

[ For Ofticial Distribution. Do Not Release to NTIS

— Orver From Sup. of Doc., U.S. Government Printing Oifice kastington, D.C. 20402, SD Cac. No. C 13

L Oriar From Narional Technical Information Service (NTIS) sringie!d, V'irginid 22151

\begin{tabular}{|l|c|}
\hline $\begin{array}{l}\text { 19. SECURITY CL.ASS } \\
\text { (THIS REPURT) } \\
\text { UNCLASSIFIED }\end{array}$ & 21. NO. OF P.AGES \\
\hline $\begin{array}{l}\text { 20. SECURITY CLASS } \\
\text { (TIISPAGE) } \\
\text { UNCLASSIFIED }\end{array}$ & 22. PrICE \\
\hline
\end{tabular}






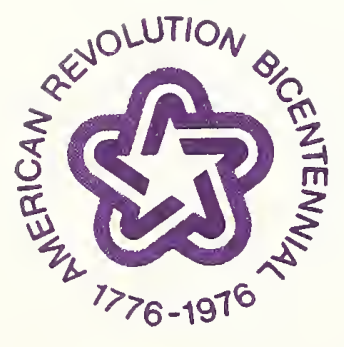



AM 
